\title{
Modelagem matemática da degradação da glicose, com produção de hidrogênio, em um reator anaeróbio de leito fixo
}

\author{
Aline Cardoso Tavares
}

Dissertação apresentada à Escola de Engenharia de São Carlos da Universidade de São Paulo, como parte dos requisitos para obtenção do título de Mestre em Engenharia Hidráulica e Saneamento.

ORIENTADOR: Prof. Dr. Marcius F. Giorgetti 
AUTORIZO A REPRODUÇÃO E DIVULGAÇÃO TOTAL OU PARCIAL DESTE TRABALHO, POR QUALQUER MEIO CONVENCIONAL OU ELETRÔNICO, PARA FINS DE ESTUDO E PESQUISA, DESDE QUE CITADA A FONTE.

Ficha catalográfica preparada pela Seção de Tratamento da Informação do Serviço de Biblioteca - EESC/USP

$\mathrm{T} 231 \mathrm{~m}$

Tavares, Aline Cardoso

Modelagem matemática da degradação da glicose, com produção de hidrogênio, em um reator anaeróbio de leito fixo / Aline Cardoso Tavares ; orientador Marcius F. Giorgetti. -- São Carlos, 2008.

Dissertação (Mestrado-Programa de Pós-Graduação em e Área de Concentração em Hidráulica e Saneamento -- Escola de Engenharia de São Carlos da Universidade de são Paulo, 2008 .

1. Saneamento. 2. Modelagem matemática. 3. Reator anaeróbio de leito fixo. 4. Produção biológica de hidrogênio. I. Título. 


\section{FOLHA DE JULGAMENTO}

Candidata: Engenheira ALINE CARDOSO TAVARES

Dissertação defendida e julgada em 30/10/2008 perante a Comissão Julgadora:

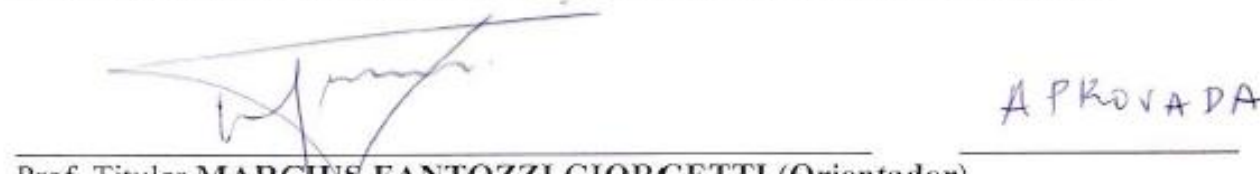

Prof. Titular MARCIUS FANTOZZI GIORGETTI (Orientador)

(Escola de Engenharia de São Carlos/USP)

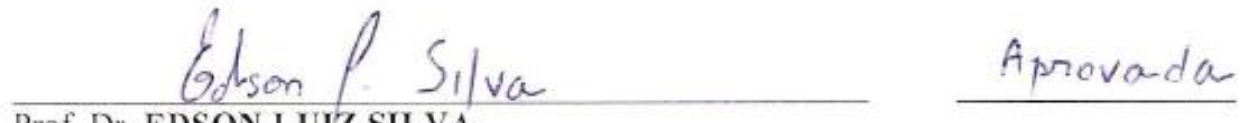

Prof. Dr. EDSON LUIZ SILVA

(Universidade Federal de São Carlos/UFSCar)



(Universidade Federal do Rio Grande do Sul/UFRGS)

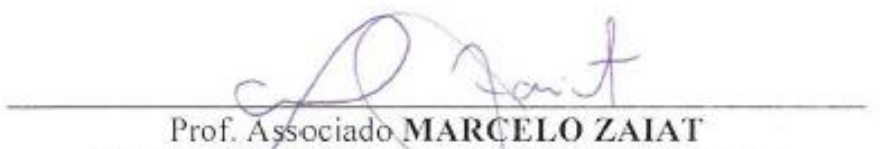

Coordenador do Programa de Pós-Graduação em

Engerharia (Hidráulica e Saneamento)

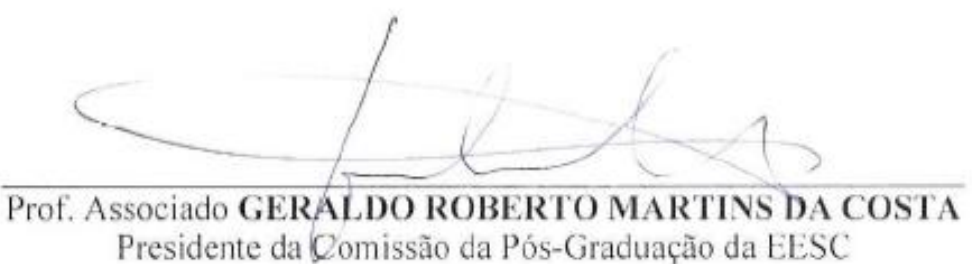


Aos meus grandes amores...

minha mãe, Marilda, pela formação do meu caráter, desprendimento e exemplos de vida e coragem, os quais haverão de nortear minha vida e minha carreira;

meus irmãos, Vivian, Denise e Vinicius, pelo estímulo, carinho e amizade;

meu namorado e amigo, Juliano, pela paciência, sincero afeto e incentivo;

Aos meus padrinhos, Helio e Gislane por seus aplausos e veemente encorajamento;

Ao meu pai, Aloizio, e à minha avó, Julia, cujas lembranças guardarei, a fim de que permaneçam vivos, para sempre, em meu coração. 
A Deus, em primeiro lugar, pelo rico dom da existência, e nesta existência, pelos que me geraram e por todos os que me cercaram, cercam e cercarão...

Ao Professor Marcius F. Giorgetti, em quem reside a competência, dedicação e finura de trato. Como abnegado sacerdote, jamais se furtou a orientar aos que bateram em sua porta. Suas excepcionais qualidades justificam o orientador de reconhecido talento e adornam o mestre completo.

Ao Professor Associado Marcelo Zaiat, a quem manifesto todo o calor do meu apreço e dever de gratidão pela eficaz participação na conclusão deste trabalho. Incansável, bondoso e amigo, sempre me incentivou à prosseguir no encalço dessa vitória.

Aos amigos Hemerson e Julio, com quem divido o prêmio dessa conquista.

Às amigas Carina, Poliana e Ana Isa, pelo incentivo da sua admiração.

Aos colegas, demais professores e funcionários do Departamento de Hidráulica e Saneamento da EESC/USP, que de alguma forma contribuíram para o engrandecimento e realização deste trabalho.

Ao Conselho Nacional de Desenvolvimento Científico e Tecnológico (CNPq), pois através do benefício da bolsa de mestrado tornou possível este estudo e minha formação. 


\section{Lista de Figuras}

FIGURA 3.1 Esquema da abordagem para o processo de modelagem.

FIGURA 4.1 Desenho esquemático do reator (unidade em $\mathrm{mm}$ ) e sua imagem fotográfica . . . . . . . . . . . . . . . 27

FIGURA 4.2 Pontos de amostragem do reator . . . . . . . . . . . . . 28

FIGURA 4.3 Representação do modelo compartimentado, em que as regiões 1 e 3 representam um reator com mistura perfeita e a região 2 , um reator tubular ideal. . . . . . . . . . . . . . .

FIGURA 4.4 Desenho esquemático do reator (unidade em $\mathrm{mm}$ ) e sua imagem ......................... 41

FIGURA 4.5 Fluxograma das etapas de desenvolvimento do modelo. . 44

FIGURA 5.1 Perfil de concentrações de ácidos propiônico e acético. 46

FIGURA 5.2 Perfil de concentrações de ácidos lático e butírico. . . . 47

FIGURA 5.3 Perfil de concentrações de álcoois. . . . . . . . . . . . . 47

FIGURA 5.4 Perfil de concentração de glicose. . . . . . . . . . . . . . 48

FIGURA 5.5 Perfil de vazão molar de hidrogênio. . . . . . . . . . . . 48

FIGURA 5.6 Resposta do modelo à variação de $+20 \%$ em $k_{4} \ldots$. . . . 49

FIGURA 5.7 Resposta do modelo à variação de $-20 \%$ em $k_{4} \ldots \ldots$. . . 49 
FIGURA 5.8 Velocidade das reações 4.2, 4.6, 4.8 e 4.10 ao longo do reator. . . . . . . . . . . . . . . 50

FIGURA 5.9 Velocidade das reações 4.4, 4.5 e 4.7 ao longo do reator. 51

FIGURA 5.10 Velocidade das reações 4.1, 4.3 e 4.9 ao longo do reator. 51

FIGURA 5.11 Simulação do perfil de concentrações de ácidos propiônico e acético. . . . . . . . . . . . . . . . . 54

FIGURA 5.12 Simulação do perfil de concentrações de ácidos lático e

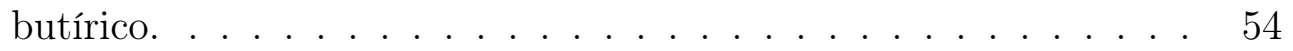

FIGURA 5.13 Simulação do perfil de concentrações de álcoois. . . . . . 55

FIGURA 5.14 Simulação do perfil de concentrações de glicose. . . . . . 55

FIGURA 5.15 Simulação do perfil de vazão molar de hidrogênio. . . . 56

FIGURA 5.16 Simulação do perfil de concentrações de ácidos para TDH $=1 \mathrm{~h} \mathrm{e} \mathrm{L}=150 \mathrm{~cm} \ldots \ldots \ldots \ldots \ldots$

FIGURA 5.17 Simulação do perfil de concentrações de ácidos para TDH $=1 \mathrm{~h} \mathrm{e} \mathrm{L}=150 \mathrm{~cm} \ldots \ldots \ldots \ldots \ldots$

FIGURA 5.18 Simulação do perfil de concentrações de álcoois para $\mathrm{TDH}=1 \mathrm{~h}$ e $\mathrm{L}=150 \mathrm{~cm} \ldots \ldots \ldots \ldots . \ldots \ldots$

FIGURA 5.19 Simulação do perfil de concentrações de glicose para $\mathrm{TDH}=1 \mathrm{~h} \mathrm{e} \mathrm{L}=150 \mathrm{~cm} \ldots \ldots \ldots \ldots$

FIGURA 5.20 Simulação do perfil de vazão molar de hidrogênio para $\mathrm{TDH}=1 \mathrm{~h} \mathrm{e} \mathrm{L}=150 \mathrm{~cm} \ldots \ldots \ldots \ldots$

FIGURA 5.21 Simulação do perfil de vazão molar de hidrogênio para diferentes valores de TDH. . . . . . . . . . . . . . . . . 59 


\section{Lista de Tabelas}

TABELA 4.1 Perfil espacial da concentração de álcoois e ácidos no reator. . . . . . . . . . . . . . . . . . 28

TABELA 5.1 Relações entre as velocidades das reações de consumo de glicose. . . . . . . . . . . . . . . . . . . . 52

TABELA 5.2 Relações entre as velocidades das reações de produção direta de $H_{2} \ldots \ldots \ldots \ldots \ldots \ldots$ 


\section{Resumo}

Modelos matemáticos oferecem grandes benefícios para a compreensão dos mecanismos envolvidos nos processos de tratamento de águas residuárias uma vez que fornecem interpretações e possibilitam previsões de desempenho, comparações de alternativas de tratamento, otimização de futuras plantas ou o aprimoramento das existentes, podendo subsidiar a elaboração de projetos em escala real. Em virtude disto, nesta pesquisa visou-se o desenvolvimento de um modelo bioquímico-matemático para descrever o processo de degradação da glicose em um reator anaeróbio de leito fixo com fluxo ascendente, com a resultante produção biológica de hidrogênio por meio do processo de fermentação. O desenvolvimento do modelo foi baseado em estudos sobre a cinética bioquímica e as características hidrodinâmicas do sistema. Os parâmetros de ajuste do modelo aos dados experimentais foram as constantes de velocidade das reações bioquímicas envolvidas na produção de hidrogênio. A calibração foi realizada manualmente buscando minimizar o desvio global. Para a determinação dos parâmetros foi utilizada a técnica de geração de números aleatórios com distribuição de frequência uniforme e em seguida, o método de inversão de matrizes. O modelo matemático se revelou bastante adequado para a previsão do perfil de concentrações ao longo do reator, e possibilitou a representação das rotas de utilização da matéria orgânica. A reação de oxidação do ácido propiônico pelas bactérias acidogênicas produtoras de hidrogênio constitui a principal via de produção de $H_{2}$ no sistema.

Palavras-chave: Modelagem matemática; Reator anaeróbio de leito fixo; Produção biológica de hidrogênio. 


\section{Abstract}

Mathematical models bring benefits to the understanding of mechanisms involved on wastewater treatment processes because they provide interpretations and make possible performance predictions, evaluation of design alternatives, optimization of future plants or the improvement to existing systems. Therefore, in this work a mathematical model to describe the glucose degradation process, with hydrogen production through the fermentation, in an upflow anaerobic packedbed reactor is developed. The model equations were based on studies of biochemical kinetics and hydrodynamics features of the system. The parameters considered were the rates of the biochemical reactions involved in the hydrogen production. The calibration was made through the minimization of the global deviation. The parameters determination was obtained with the use of a technique of generation of aleatory numbers, and after that, the method of matrices inversion for the solution of the system of linear equations. The mathematical model developed showed to be adequate for the concentrations prediction along the reactor, and it made possible the representation of the routes of organic material utilization. The oxidation reaction of propionic acid is the main hydrogen production route in the reactor.

Keywords: Mathematical models; Upflow anaerobic packed-bed reactor; Hydrogen production. 


\section{Sumário}

$\begin{array}{ll}\text { Lista de Figuras } & \text { ix }\end{array}$

Lista de Tabelas

Resumo xiii

Abstract $\quad$ Xv

1 Introdução 1

2 Objetivos 5

2.1 Objetivo geral . . . . . . . . . . . . . . . . . 5

2.2 Objetivos específicos . . . . . . . . . . . . . . 5 5

$\begin{array}{llr}3 & \text { Revisão Bibliográfica } & 7\end{array}$

3.1 Modelagem . . . . . . . . . . . . . . . . 7

3.1.1 Princípios da modelagem . . . . . . . . . . 7

3.1.2 Uso da modelagem em processos de tratamento . . . . . . 11

3.1.3 Modelo compartimentado . . . . . . . . . . . . . 12

3.2 Métodos numéricos . . . . . . . . . . . . . . . . . . . . . . . . 12

3.2.1 Método dos mínimos quadrados . . . . . . . . . . . . . 13

3.2.2 Método de inversão de matrizes . . . . . . . . . . . . . . . 14

3.3 Combustíveis fósseis e energia nuclear . . . . . . . . . . . . . . . 15

3.4 O hidrogênio como energia renovável . . . . . . . . . . . . . 16

3.5 Bioprodução de hidrogênio . . . . . . . . . . . . . . . . . 17

3.6 Reator anaeróbio de leito fixo . . . . . . . . . . . . . . 23

4 Modelagem 25 
4.1 Considerações iniciais . . . . . . . . . . . . . . . . . 25

4.2 Dados experimentais . . . . . . . . . . . . . . . 27

4.3 Formulação do modelo . . . . . . . . . . . . . . . . . . . . . 29

4.3.1 Reações envolvidas no processo . . . . . . . . . . . 30

4.3.2 Balanço material . . . . . . . . . . . . . 35

4.4 Metodologia de resolução . . . . . . . . . . . . . . . . . . 40

5 Resultados $\quad 45$

5.1 Constantes cinéticas . . . . . . . . . . . . . . 45

5.2 Ajuste do modelo . . . . . . . . . . . . . . . . 46

5.3 Rotas de formação de $H_{2}$. . . . . . . . . . . . . . . . . . . . . . 49

5.4 Simulação . . . . . . . . . . . . . . . . . . . 53

6 Conclusões $\quad 61$

$\begin{array}{lll}7 & \text { Sugestões de Continuidade } & 63\end{array}$

$\begin{array}{ll}\text { Referências Bibliográficas } & 65\end{array}$ 


\section{Capítulo 1}

\section{Introdução}

No setor industrial, em geral, os processos de conversão de matérias-primas em produtos não atingem $100 \%$ de eficiência e nem todos os insumos utilizados irão compor o produto final. Isso implica na geração de resíduos nas mais variadas formas, inclusive como efluentes líquidos, uma vez que a água é amplamente utilizada para assimilar e transportar contaminantes. No entanto, o panorama de escassez hídrica somado à rigidez das legislações - que deve ser cada vez maior tendo em vista o cenário ambiental insustentável - vêm incentivando a busca por soluções que viabilizem as atividades industriais, seja no aspecto econômico, como no ambiental e social.

Dentro desse contexto, destaca-se a necessidade de adequar as características das águas residuárias geradas nos processos industriais aos padrões de emissão estabelecidos em normas ou em níveis apropriados para formas de reúso subsequentes. Isso é feito por meio da utilização de operações e processos unitários de tratamento que sejam capazes de reduzir a concentração dos contaminantes presentes.

A aplicabilidade dos processos anaeróbios de tratamento de efluentes é favorecida pelas condições econômicas, ambientais e sócio-culturais no país, quando comparados aos sistemas aeróbios, de um modo geral, devido à menor produção de sólidos, menor requerimento de nutrientes e baixo custo de implantação, 
operação e manutenção, em virtude, principalmente, do reduzido consumo de energia (CHERNICHARO, 1997).

Os custos de operação e implantação de estações de tratamento de águas residuárias dependem também do nível de eficiência imposta e do grau de dificuldades construtivas e operacionais, direcionando o foco dos estudos atuais para as alternativas de otimização dos processos de digestão dos poluentes.

Nesse sentido, alguns estudos têm buscado aliar o tratamento de águas residuárias à produção biológica de hidrogênio em reatores anaeróbios, com o intuito de utilizar esse gás para a geração de energia, como alternativa ao uso de combustíveis fósseis. Essa tecnologia contribui para minimizar o aquecimento global, uma vez que a água é o produto da combustão do hidrogênio, enquanto os combustíveis fósseis geram gás carbônico, o maior responsável pela elevação da temperatura.

Além disso, o hidrogênio é um combustível renovável em potencial, que apresenta alta conversão de energia por unidade de massa $\left(122 \mathrm{~kJ} \mathrm{~g}^{-1}\right)$ (LAY et al., 1999).

A aplicação de hidrogênio em célula a combustível promove a geração de eletricidade ao converter os elementos químicos hidrogênio e oxigênio em água. O hidrogênio, portanto, possibilita o transporte de combustível e o armazenamento de energia, o que o torna uma tecnologia chave para um futuro possivelmente dominado pela energia renovável (ZERTA et al., 2008).

De modo a ampliar o conhecimento sobre a bioprodução de hidrogênio a partir de águas residuárias, nesta pesquisa visou-se analisar o processo de degradação da glicose com formação de hidrogênio, por meio de fundamentos de modelagem e de técnicas de simulação, estimando parâmetros por meio de algoritmos de otimização, ajustando o modelo a dados experimentais.

Os modelos matemáticos utilizados nos processos biológicos de águas residuárias são fundamentais, uma vez que descrevem as características dinâmicas do sistema, fornecendo conceitos e possibilitando respostas, previsões ou comparações 
de alternativas, propiciando o controle e a otimização de tecnologias (CHRISTOFOLETTI et al., 2004).

Entretanto, fatores como composição, pH, temperatura do meio, adaptabilidade e heterogeneidade das populações celulares, interações entre a biomassa e o meio (transferência de nutrientes, produtos e calor), dentre outros, podem influenciar na cinética dos microrganismos, e dificultar o desenvolvimento de modelos cinéticos que englobem todos os aspectos e detalhes da relação meio/ biomassa. Assim, são adotadas simplificações para que os modelos se tornem aplicáveis (FORESTI et al., 1999).

Os dados cinéticos fornecem informações úteis para a análise de sistemas de tratamento, as quais podem ser obtidas por meio de balanços de massa em reatores bioquímicos usados no tratamento de águas residuárias.

O modelo proposto é um modelo compartimentado que sugere a divisão do reator, de modo a possibilitar uma analogia entre os padrões de escoamento em reatores ideais nas regiões formadas.

O desenvolvimento do modelo foi baseado em estudos sobre a cinética bioquímica e as características hidrodinâmicas do sistema. Os parâmetros de ajuste do modelo aos dados experimentais foram as constantes de velocidade das reações bioquímicas envolvidas no processo de produção biológica de hidrogênio. 


\section{Capítulo 2}

\section{Objetivos}

\subsection{Objetivo geral}

O objetivo principal neste trabalho foi o desenvolvimento de um modelo bioquímico-matemático para descrever o processo de degradação da glicose, formando, principalmente, ácidos, álcoois, e hidrogênio em um reator anaeróbio de leito fixo com fluxo ascendente, com a previsão do perfil espacial da concentração do substrato ao longo do reator.

Dados experimentais produzidos por PEIXOTO (2008) foram utilizados para a calibração do modelo.

\subsection{Objetivos específicos}

Os objetivos específicos foram:

- A obtenção das constantes de velocidade das reações (parâmetros do modelo) envolvidas no processo de produção biológica de hidrogênio;

- Analisar as prováveis rotas metabólicas de formação do hidrogênio;

- A simulação do comportamento do sistema para diferentes condições de operação. 


\section{Capítulo 3}

\section{Revisão Bibliográfica}

\subsection{Modelagem}

\subsubsection{Princípios da modelagem}

Na literatura, existem diversas definições para modelos. Algumas delas são:

- Representação de algum sistema, numa linguagem ou forma de fácil acesso e uso, com o objetivo de entendê-lo e buscar respostas para diferentes entradas (TUCCI, 1998);

- Reprodução idealizada de algumas ou todas as características físicas de um processo (WENDLAND e RÜBER, 1998);

- Uma abstração da realidade utilizada para se obter clareza conceitual, podendo reduzir a variedade e complexidade do mundo real a um nível que se possa entender e representar (LEE, 1973);

Modelos matemáticos buscam descrever a natureza de um sistema por meio de uma estrutura teórica representada por equações matemáticas, valores numéricos dos parâmetros das equações, e dados de entrada e de saída, frequentemente compreendendo observações/medições de campo ou de laboratório, e relacionando 
fatores externos com a resposta do sistema. Para TUCCI (1998), estes modelos são versáteis porque se pode facilmente modificar a sua lógica, obtendo-se resultados de diferentes situações de um mesmo sistema ou de diferentes sistemas, além da alta velocidade de resposta.

A desvantagem deste tipo de modelo está na discretização de processos contínuos e na dificuldade da representação matemática de toda a complexidade das múltiplas interações nos sistemas ambientais, várias delas não mensuráveis ou quantificáveis.

De acordo com a forma de descrever o sistema e a maneira como as equações são resolvidas, os modelos matemáticos podem ser classificados em distribuído, concentrado, mecanístico, empírico, estacionário, dinâmico, determinístico ou estocástico.

Os modelos distribuídos (ou modelos de parâmetros distribuídos) são aqueles nos quais se admite que as propriedades de um constituinte variam com as coordenadas espaciais. Tem-se como exemplo o reator tubular ideal, que é caracterizado por apresentar perfis de velocidade, temperatura e concentração uniformes em uma seção transversal. O fluxo se processa como "êmbolos"que fluem de montante para jusante, sem mistura e/ou dispersão de substâncias entre os êmbolos. Os modelos concentrados são aqueles nos quais as propriedades são assumidas como uniformes e independentes da posição. É o caso do reator com mistura perfeita que, como o nome sugere, apresenta sua composição uniforme dentro do reator; portanto, a concentração de saída é igual à concentração no seu interior.

PINTO e LAGE (2001) descrevem os modelos mecanísticos como aqueles desenvolvidos a partir de pressupostos teóricos que representam de forma fundamentada os vários aspectos envolvidos no problema. Em contraste, os modelos empíricos não buscam referências explícitas ao que ocorre dentro do processo, apenas enfocam o que é mensurável: as variáveis de entrada e saída do modelo. $\mathrm{Na}$ realidade, estas duas categorias de modelos caracterizam os dois extremos do espectro, e a maioria dos modelos se situa dentro destes dois limites. 
Os modelos dinâmicos consideram as variações temporais e espaciais das variáveis envolvidas no modelo. Podem ser utilizados em uma gama mais ampla de problemas de interesse e são fundamentais para descrever operações descontínuas. Por se tratar de representações mais complexas, frequentemente são introduzidas simplificações, no sentido de assumir que todas as variáveis do modelo são constantes ao longo do tempo. Estes modelos são denominados de modelos estacionários e são mais utilizados para o projeto de unidades de operações contínuas.

Segundo CHOW (1964, citado por TUCCI, 1998), se a chance de ocorrência das variáveis é levada em conta, e o conceito de probabilidade é introduzido na formulação do modelo, o processo e o modelo são ditos estocásticos. De outro lado, se a chance de ocorrência das variáveis envolvidas no processo é ignorada, e o modelo segue uma lei que não a lei das probabilidades, o modelo e os processos são ditos determinísticos.

A escolha de se utilizar uma representação matemática em relação a outra depende das características e particularidades dos sistemas.

Um procedimento para a construção de modelos consiste numa sequência de normas e caminhos que induzem à produção de um modelo, à implementação de algum tipo de linguagem formal, ao estabelecimento de deduções e à avaliação dessas inferências em face da adequabilidade e do uso para o qual o modelo foi desenvolvido (CHRISTOFOLETTI, 2004). A Figura 3.1.1 apresenta um fluxograma da sequência de desenvolvimento de um modelo matemático.

Deve-se notar o caráter iterativo do processo de modelagem, com possíveis retornos a etapas anteriores para reajustes na estrutura do modelo, no algoritmo e/ou nos valores dos parâmetros. 




Figura 3.1: Esquema da abordagem para o processo de modelagem.

Fonte: CHRISTOFOLETTI (2004) 


\subsubsection{Uso da modelagem em processos de tratamento}

De acordo com JORGENSEN e GROMIEC (1985), os processos de tratamento biológico de águas residuárias são utilizados há pelo menos cem anos. No entanto, há uma necessidade contínua de melhor entendimento sobre esses processos. Os modelos matemáticos oferecem grandes benefícios para esse avanço, fornecendo conceitos e possibilitando respostas, previsões de desempenho ou comparações de alternativas de tratamento, propiciando o controle e a otimização de tecnologias (CHRISTOFOLETTI, 2004).

Outra vantagem dos modelos matemáticos refere-se à potencial economia na construção e nos custos de operação e manutenção, uma vez que qualquer processo de tratamento adequado deve produzir o efluente específico com o consumo mínimo de energia e de insumos (JORGENSEN e GROMIEC, 1985).

Os modelos matemáticos utilizados nos processos de tratamento biológicos podem ser utilizados também para (OLSSON e NEWELL, 1999):

- Planejamento/gerenciamento a longo prazo. Análise da aplicabilidade de projetos de novos processos, o aprimoramento de projetos existentes, ou a avaliação técnica e econômica de alternativas de tratamento;

- Controle em tempo real, no caso do controle integrado de estações de tratamento de esgotos e do corpo d'água receptor, ou no caso da avaliação de eventos transientes (como uma carga poluidora acidental) ou de comportamentos sazonais;

- Outorga para lançamentos de efluentes;

- Atenuação de problemas, podendo possibilitar a manutenção do desempenho ótimo da estação durante mudanças operacionais forçadas, por exemplo, a falha de equipamentos por um longo período. Possibilita também a investigação de acidentes ou falhas e suas medidas preventivas; 
- Otimização operacional, como o planejamento de funcionamento e paralisação de estações de tratamento, e a minimização de erros, programando os processos de bateladas ou a distribuição de vazão nas unidades;

- Pesquisa, explorando as consequências de novos conhecimentos e explicando adequadamente os fenômenos significativos dentro do processo, melhorando a compreensão de um sistema.

\subsubsection{Modelo compartimentado}

O modelo compartimentado é utilizado para a descrição dos escoamentos ideais.

O escoamento ideal pode ser descrito por meio de dois tipos básicos de reatores bioquímicos: os do tipo descontínuos, nos quais o reator é carregado com os reagentes, onde são bem misturados e a mistura resultante é descarregada após certo tempo de reação; e os reatores contínuos, onde reagentes e produtos entram e saem continuamente. A tendência atual é a aplicação de reatores contínuos, uma vez que sua produtividade é maior para o tratamento em larga escala, e pela viabilidade econômica, quando comparados com os do tipo descontínuos (LEVENSPIEL, 1999). Os reatores com mistura perfeita (Continuous Stirred Tank Reactor - CSTR) e os tubulares (Plug Flow Reactor - PFR), são os reatores contínuos ideais comumente citados na literatura, diferenciados pelas condições de mistura.

O modelo compartimentado sugere a divisão do reator, de modo a possibilitar uma analogia entre reatores ideais e as regiões formadas, tratando-as como reatores em série ou paralelo.

\subsection{Métodos numéricos}

Os métodos numéricos correspondem a um conjunto de ferramentas utilizado para se obter a solução de problemas matemáticos de forma aproximada. Estes 
métodos se aplicam a problemas que não apresentam uma solução exata, portanto precisam ser resolvidos numericamente.

Embora existam diversas metodologias de resolução, nesta pesquisa limitase apenas ao método dos mínimos quadrados e à solução direta do sistema de equações por meio da inversão de matrizes.

\subsubsection{Método dos mínimos quadrados}

O objetivo deste método é aproximar uma função $f$ por outra $g$, escolhida de uma família de funções em duas situações distintas: no domínio discreto e no domínio contínuo.

No domínio contínuo, a função $f$ é dada por sua forma analítica $(y=f(x))$. Aproxima-se $f(x), x \in[a, b]$, por um polinômio de grau máximo $m$, isto é,

$$
f(x)=a_{0}+a_{1} x_{1}+\ldots+a_{m} x_{m}=P_{m}(x)=g(x)
$$

de tal modo que a distância de $P_{m}$ a $f$ seja mínima.

Usando a definição de distância, tem-se que os coeficientes $a_{0}, a_{1}, \ldots, a_{m}$ são tais que

$$
\int_{a}^{b}\left[f(x)-P_{m}(x)\right]^{2} d x
$$

seja o menor possível.

No domínio discreto, a função $f$ é dada por uma tabela de valores. Para a função dada por $n+1$ pares de pontos $\left(x_{0}, y_{0}\right),\left(x_{1}, y_{1}\right), \ldots,\left(x_{n}, y_{n}\right)$, em que $y_{i}=\mathrm{f}\left(x_{i}\right), i=0,1, \ldots, n$, com os $n+1$ pontos distintos, determina-se um polinômio (com coeficientes reais)

$$
f(x)=a_{0}+a_{1} x_{1}+\ldots+a_{m} x_{m}=P_{m}(x)=g(x)
$$


de grau máximo $m(m<n)$ e tal que

$$
\sum_{k=0}^{n}\left[y_{k}-P_{m}\left(x_{k}\right)\right]^{2}
$$

seja mínima.

\subsubsection{Método de inversão de matrizes}

A inversão matricial pode ser utilizada para a resolução numérica de um sistema linear de n equações com n incógnitas, cuja forma matricial está representada pela equação 3.1 .

$$
A x=b
$$

$$
\left|\begin{array}{cccc}
a_{11} & a_{12} & \cdots & a_{1 n} \\
a_{21} & a_{22} & \cdots & a_{2 n} \\
\vdots & \cdots & \ddots & \vdots \\
a_{m 1} & a_{m 2} & \cdots & a_{m n}
\end{array}\right|\left|\begin{array}{c}
x_{1} \\
x_{2} \\
\vdots \\
x_{m}
\end{array}\right|=\left|\begin{array}{c}
b_{1} \\
b_{2} \\
\vdots \\
b_{m}
\end{array}\right|
$$

em que $a_{i j}$ são os coeficientes; $x_{j}$ são as variáveis; e $b_{i}$ são as constantes tal que $1 \leq i \leq m$ e $1 \leq j \leq n$. A é a matriz dos coeficientes; $x$ é o vetor de incógnitas (ou vetor solução); e $b$ é o vetor dos termos independentes.

A inversa de uma matriz quadrada $A$ é a matriz $A^{-1}$, tal que $A A^{-1}=I=$ $A^{-1} A$. A matriz identidade, $I$, é a matriz com elementos da diagonal principal iguais a 1 e com todos os outros elementos nulos. Apenas as matrizes quadradas ditas não singulares, isto é, aquelas que possuem o determinante diferente de zero, admitem sua inversa. Multiplicando a equação (3.1) pela matriz inversa de $A$, tem-se:

$$
A^{-1} A x=A^{-1} b \rightarrow I x=x=A^{-1} b
$$

Dessa forma, a matriz solução $x$ é obtida pelo produto vetorial da matriz inversa de $A$ pelo vetor dos termos independentes. A solução do sistema será 
a solução trivial, ou seja, o vetor $x$ será nulo, se $b$ também for um vetor nulo (constantes nulas).

\subsection{Combustíveis fósseis e energia nuclear}

De acordo com a Agência Internacional de Energia (IEA), espera-se que a produção mundial de petróleo aumente mais de $60 \%$ nos próximos 25 anos para atender a demanda futura. Entretanto, estudos reveladores do perfil temporal da produção de petróleo em jazidas individuais indicam que o auge da produção global é iminente e provavelmente ocorrerá antes de 2010. Depois disso, a expectativa é que haja um declínio de 2 a $3 \%$ ao ano, sendo que em algumas regiões, o declínio pode chegar a mais de $10 \%$ ao ano (ZERTA et al., 2008).

Em contraste com a produção de petróleo, em que um decaimento na produção regional pode ser compensado por importações, o mercado de gás natural é predominantemente regional. Espera-se que o auge da produção mundial deste combustível fóssil ocorra entre 2015 e 2020, e seja provocado pelo pico da produção de seu maior produtor, a Rússia (ZERTA et al., 2008).

Um estudo realizado pelo Energy Watch Group sobre as fontes mundiais de carvão vegetal revelou uma substancial diminuição em seu número nas últimas décadas. Nos últimos 25 anos, as estimativas para estes recursos diminuíram de 10.000 bilhões de toneladas de carvão para aproximadamente 5.000 bilhões de toneladas. A tendência é a diminuição progressiva destas fontes.

De acordo com ZERTA et al. (2008), a maior parte das usinas nucleares foi construída entre as décadas de 70 e 80. Desde então, a instalação de novos reatores tem diminuído progressiva e consideravelmente. Em 2007, havia 436 unidades de reatores em operação em todo o mundo (Agência Internacional de Energia Atômica - IAEA). Com uma vida útil estimada em 40 anos, aproximadamente $75 \%$ dos reatores terão que ser substituídos até 2030 para que estabilize o fornecimento de energia proveniente do setor nuclear, isto é, 14 novos reatores por ano em média. É provável que isto não ocorra uma vez que apenas 28 reatores 
estão em construção, com previsão de início de operação para 5 a 7 anos.

Ainda, segundo a Agência de Energia Nuclear e a IAEA, uma análise das reservas de urânio mostra que a energia nuclear não será capaz de substituir aquelas produzidas pelo gás natural, pelo carvão ou pelo petróleo.

A única alternativa permenente e viável para suprir as necessidades humanas e produzir o menor impacto ambiental possível é adotar um modelo de economia sustentável, baseado na geração de energia e bens de consumo a partir de recursos naturais renováveis e reciclagem ou tratamento de resíduos produzidos durante a produção e no pós-consumo.

A busca por alternativas que visem a sustentabilidade é vista pela maioria dos países como o caminho para a libertação da dependência econômica do petróleo e, consequentemente, o fim da submissão ao aumento progressivo no preço do barril de petróleo.

\subsection{O hidrogênio como energia renovável}

As consequências ao meio ambiente provocadas pelo intenso uso de combustíveis fósseis na geração de energia são evidentes. Os gases gerados na combustão desses combustíveis são uma das principais causas do aquecimento global e da chuva ácida, os quais afetam o clima do planeta, as condições do tempo, a vegetação e o ecossistema aquático. Em decorrência disso, há um grande interesse no desenvolvimento de fontes de energia renováveis e menos agressivas ao meio ambiente (KHANAL et at, 2004).

Neste contexto, o hidrogênio $\left(H_{2}\right)$ é um combustível renovável em potencial e sua combustão não gera gases potencializadores do efeito estufa. Desta forma, dependendo de como é produzido, o $H_{2}$ pode ser considerado um combustível limpo.

O hidrogênio produz 2,75 vezes mais energia do que os hidrocarbonetos (LAY et al., 1999; MIZUNO et al., 2000) e apresenta alta conversão de energia por 
unidade de massa $\left(122 k J g^{-1}\right)$. Em virtude disto, este gás pode ser utilizado como alternativa promissora ao uso de combustíveis fósseis.

Hoje, o uso do hidrogênio é visto principalmente no setor de transportes. No entanto, de acordo com ZERTA et al. (2008), não é esperado que os veículos movidos a energia elétrica satisfaçam as expectativas de todos os usuários no futuro por apresentarem limitações práticas (como a distância percorrida e o longo período para recarregar). Porém, alguns estudos mostram que estas limitações são pequenas quando comparadas à eficiência e às emissões geradas pela combustão do hidrogênio.

A aplicação de hidrogênio em célula combustível gera energia elétrica, ou seja, o hidrogênio promove o transporte de combustível e o armazenamento de energia, o que o torna uma tecnologia chave para um futuro dominado pela energia renovável. O funcionamento destas células baseia-se em um sistema eletrocatalítico capaz de utilizar o potencial máximo do combustível e produzir o mínimo de poluentes (WENDT et al., 2000).

\subsection{Bioprodução de hidrogênio}

Os processos básicos para a produção de hidrogênio utilizando fontes primárias não provenientes de combustíveis fósseis são: a eletrólise da água, os processos termoquímicos, os processos radiolíticos e os processos biológicos (LAY et al., 1999). A produção biológica de hidrogênio pode ser conseguida por meio de dois processos: fermentação ou fotossíntese. O processo fermentativo, além de possibilitar o tratamento de águas residuárias, é a forma mais simples e atraente de obtenção do gás, pois é uma tecnologia de baixo custo quando comparada a outros processos, requer menos energia para a sua geração e apresenta altas taxas de formação (MIZUNO et al., 2000).

A digestão anaeróbia é um processo biológico natural que ocorre na ausência de oxigênio molecular no qual uma comunidade de microrganismos interage para promover a fermentação estável e auto-regulada da matéria orgânica, resultando 
principalmente, os gases metano e dióxido de carbono (MOSEY, 1982). Este processo pode ser dividido em quatro fases principais.

A primeira fase consiste na hidrólise de materiais particulados complexos (polímeros) em materiais dissolvidos mais simples (moléculas menores), que são capazes de atravessar as paredes celulares das bactérias fermentativas. Esta conversão é conseguida por meio da ação de exoenzimas excretadas pelas bactérias fermentativas hidrolíticas. Na anaerobiose, a hidrólise dos polímeros usualmente ocorre de forma lenta, sendo vários os fatores que podem afetar o grau e a taxa em que o substrato é hidrolisado: pH do meio, tamanho das partículas, composição do substrato, tempo de residência do substrato no reator, temperatura operacional do reator, concentração de $\mathrm{NH}_{4}^{+}-\mathrm{N}$, concentração de produtos da hidrólise (LETTINGA et al., 1996).

Na segunda fase, denominada acidogênese, de acordo com CHERNICHARO (1997), os produtos solúveis provenientes da fase de hidrólise são metabolizados no interior das células das bactérias fermentativas, sendo convertidos em diversos compostos mais simples, que são excretados pelas células. Os compostos produzidos incluem ácidos graxos voláteis, álcoois, ácido lático, gás carbônico, hidrogênio, amônia e sulfeto de hidrogênio, além de novas células bacterianas. Como os ácidos graxos voláteis são o principal produto dos organismos fermentativos, estes organismos são geralmente designados bactérias fermentativas acidogênicas.

Na terceira fase, a acetogênese, ocorre a oxidação dos produtos oriundos da acidogênese em compostos que serão utilizados como substrato para a produção de metano como o hidrogênio, o dióxido de carbono e o acetato. Esta oxidação é realizada pelas bactérias acetogênicas.

A última etapa no processo de degradação anaeróbia é denominada metanogênese. As bactérias metanogênicas utilizam um número limitado de substratos, compreendendo ácido acético, hidrogênio e dióxido de carbono, ácido fórmico, metanol, metilaminas e monóxido de carbono. O metano pode ser produzido pelas bactérias metanogênicas hidrogenotróficas a partir de hidrogênio e dióxido de carbono, ou pelas bactérias metanogênicas acetoclásticas a partir do ácido 
acético ou metanol (CHERNICHARO, 1997).

Neste contexto, MOSEY (1983) desenvolveu um modelo matemático para descrever o processo de digestão anaeróbia e considerou as seguintes reações de degradação da glicose:

- Processo acidogênico

$$
\begin{aligned}
& \mathrm{C}_{6} \mathrm{H}_{12} \mathrm{O}_{6} \rightarrow \mathrm{C}_{4} \mathrm{H}_{8} \mathrm{O}_{2}+2 \mathrm{CO}_{2}+2 \mathrm{H}_{2} \\
& \text { glicose ác. butírico } \\
& \mathrm{C}_{6} \mathrm{H}_{12} \mathrm{O}_{6}+2 \mathrm{H}_{2} \mathrm{O} \rightarrow 2 \mathrm{C}_{2} \mathrm{H}_{4} \mathrm{O}_{2}+2 \mathrm{CO}_{2}+4 \mathrm{H}_{2} \\
& \text { glicose ác. acético } \\
& \mathrm{C}_{6} \mathrm{H}_{12} \mathrm{O}_{6}+2 \mathrm{H}_{2} \rightarrow 2 \mathrm{C}_{3} \mathrm{H}_{6} \mathrm{O}_{2}+2 \mathrm{H}_{2} \mathrm{O} \\
& \text { glicose ác. propiônico }
\end{aligned}
$$

- Processo acetogênico

$$
\mathrm{C}_{4} \mathrm{H}_{8} \mathrm{O}_{2}+2 \mathrm{H}_{2} \mathrm{O} \rightarrow 2 \mathrm{C}_{2} \mathrm{H}_{4} \mathrm{O}_{2}+2 \mathrm{H}_{2}
$$

ác. butírico ác. acético

$$
\mathrm{C}_{3} \mathrm{H}_{6} \mathrm{O}_{2}+2 \mathrm{H}_{2} \mathrm{O} \rightarrow \mathrm{C}_{2} \mathrm{H}_{4} \mathrm{O}_{2}+\mathrm{CO}_{2}+3 \mathrm{H}_{2}
$$

ác. propiônico ác. acético

- Processo metanogênico

$$
\mathrm{C}_{2} \mathrm{H}_{4} \mathrm{O}_{2} \rightarrow \mathrm{CH}_{4}+\mathrm{CO}_{2}
$$

ác. acético

$$
4 \mathrm{H}_{2}+\mathrm{CO}_{2} \rightarrow \mathrm{CH}_{4}+2 \mathrm{H}_{2} \mathrm{O}
$$

COSTELLO et al. (1991) desenvolveram um modelo dinâmico para descrever o metabolismo anaeróbio em um reator de alta taxa. Os autores consideraram as seguintes reações de degradação da glicose dos processos acidogênico e acetogênico, além daquelas citadas anteriormente: 
- Processo acidogênico

$\mathrm{C}_{6} \mathrm{H}_{12} \mathrm{O}_{6} \rightarrow 2 \mathrm{C}_{3} \mathrm{H}_{6} \mathrm{O}_{3}$

glicose ác. lático

$\mathrm{C}_{3} \mathrm{H}_{6} \mathrm{O}_{3}+\mathrm{H}_{2} \rightarrow \mathrm{C}_{3} \mathrm{H}_{6} \mathrm{O}_{2}+\mathrm{H}_{2} \mathrm{O}$

ác. lático ác. propiônico

- Processo acetogênico

$\mathrm{C}_{3} \mathrm{H}_{6} \mathrm{O}_{3}+\mathrm{H}_{2} \mathrm{O} \rightarrow \mathrm{C}_{2} \mathrm{H}_{4} \mathrm{O}_{2}+\mathrm{CO}_{2}+2 \mathrm{H}_{2}$

ác. lático ác. acético

GAVALA et al. (2005) compararam o desempenho entre um CSTR e um reator de manta de lodo (UASB) para a produção de hidrogênio pela etapa fermentativa. Para representar a formação de etanol a partir da glicose, os autores utilizaram a reação:

$$
\underset{\text { glicose }}{\mathrm{C}_{6} \mathrm{H}_{12} \mathrm{O}_{6}} \underset{\text { etanol }}{2 \mathrm{C}_{2} \mathrm{H}_{6} \mathrm{O}}+2 \mathrm{CO}_{2}
$$

Analisando as reações envolvidas na digestão anaeróbia, nota-se que a maximização da produção de hidrogênio pode ser alcançada por meio da inibição do processo metanogênico. Esta inibição pode ser obtida pela variação de parâmetros operacionais em reatores anaeróbios, tais como: pH (VAN GINKEL et. al., 2001), material suporte para a adesão da biomassa, concentração do substrato (VAN GINKEL e LOGAN, 2005), temperatura (GAVALA et al., 2006) e tempo de detenção hidráulica (TDH) (CHEN et al., 2004).

De acordo com HAWKES et al. (2002), os carboidratos apresentam-se como fonte preferencial de carbono orgânico para a produção de hidrogênio por meio da fermentação.

A Tabela 3.1 mostra o rendimento da produção de hidrogênio obtido a partir de diferentes substratos e processos. 


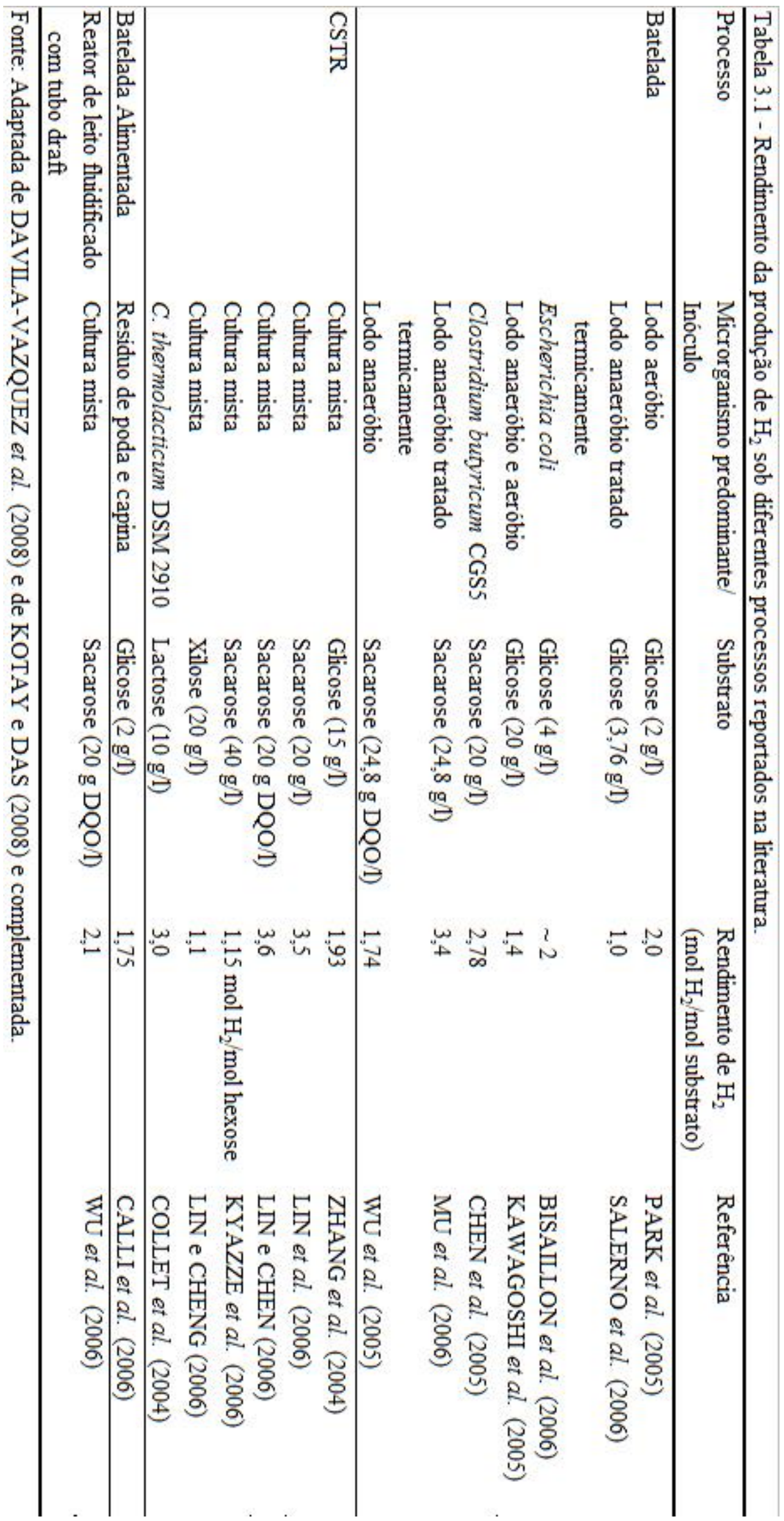




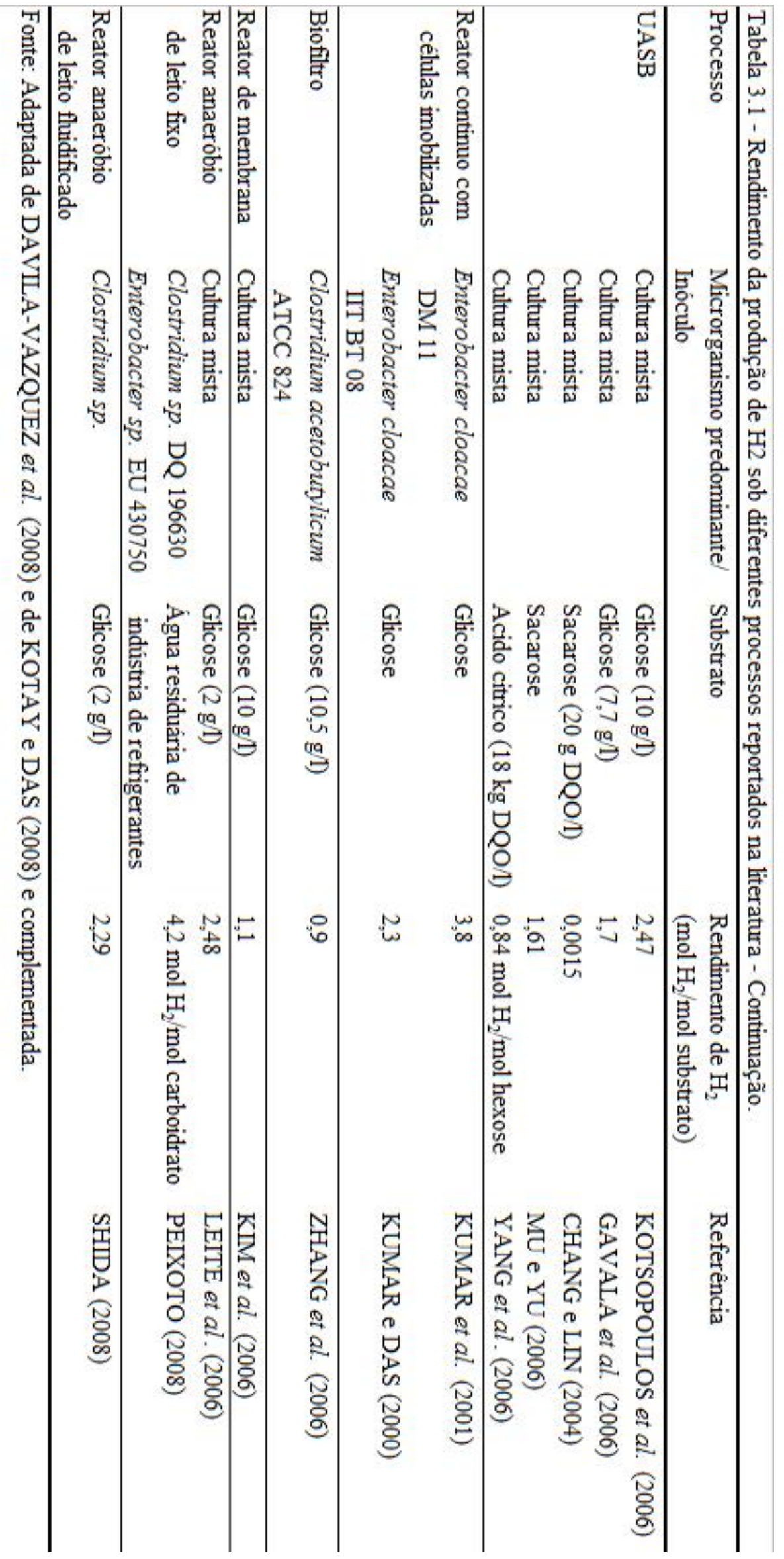




\subsection{Reator anaeróbio de leito fixo}

A partir da década de 60, com o advento da imobilização de enzimas para uso industrial, surgiu o interesse na imobilização de microrganismos para o uso em processos contínuos de tratamento de águas residuárias, uma vez que um dos principais problemas encontrados nos processos biológicos contínuos é o arraste de microrganismos juntamente com o líquido e sua perda no efluente. Essa perda de biomassa é prejudicial ao processo, uma vez que o desempenho do reator é função da massa de microrganismos presentes e das velocidades das reações bioquímicas. A imobilização da biomassa responsável pela degradação da matéria orgânica proporcionou o surgimento de novas concepções de reatores operados de modo contínuo, como o de leito fluidificado/expandido, o reator de manta de lodo e fluxo ascendente (UASB) e reatores de leito fixo (CABRAL, 1995).

Dentro deste contexto, os reatores anaeróbios de leito fixo apresentam-se como alternativa promissora devido ao seu bom desempenho na remoção de matéria orgânica, estabilidade e também em virtude da sua capacidade de manter alto o tempo de retenção celular mesmo quando operados com baixo tempo de detenção hidráulica (ZAIAT et al., 1996).

Estes reatores formam, ao longo de seu comprimento, um leito catalítico empacotado por onde flui a matéria orgânica que é consumida pelo metabolismo anaeróbio. A imobilização da biomassa em meio suporte aliada à grande relação comprimento/diâmetro promove um escoamento com comportamento que pode ser próximo de um reator tubular ideal de fluxo pistonado.

Deste modo, os modelos matemáticos podem se tornar ferramentas fundamentais para o sucesso da aplicação prática dessa configuração de reator, uma vez que relacionam tanto os parâmetros hidráulicos como os cinéticos envolvidos no processo, minimizando a influência do aumento de escala no desempenho do reator. 


\section{Capítulo 4}

\section{Modelagem}

\subsection{Considerações iniciais}

Os dados experimentais utilizados para a calibração do modelo desenvolvido foram produzidos por PEIXOTO (2008), cuja pesquisa objetivou promover a produção biológica de hidrogênio em reatores anaeróbios de leito fixo com fluxo ascendente, utilizando polietileno de baixa densidade como material para a adesão da biomassa.

Os reatores utilizados pelo autor possuíam o diâmetro interno de $80 \mathrm{~mm}$, diâmetro externo de $88 \mathrm{~mm}$ e $750 \mathrm{~mm}$ de comprimento. Cada reator foi dividido em três compartimentos: entrada do afluente (área de mistura), saída de efluente (zona de separação das fases líquidas e gasosas) e leito contendo material suporte.

Os reatores foram mantidos em uma câmara climatizada com temperatura média de $25^{\circ} \mathrm{C}$ e alimentados continuamente com água residuária sintética preparada de modo a simular o efluente de uma indústria de refrigerantes (Bebidas São Carlos Ltda., São Carlos, SP).

Os ácidos foram determinados por Cromatografia Líquida de Alta Eficiência (CLAE) no cromatógrafo Shimadzu, de acordo com metodologia desenvolvida no LPB. As condições para as análises cromatográficas foram: 
- Coluna de troca iônica: Aminex HPX-87H;

- Fase móvel: $\mathrm{H}_{2} \mathrm{SO}_{4}$ 0,005M;

- Fluxo: 0,6 ml/min;

- Detector de UV: Arranjo de diodos 205 nm;

- Volume de amostra: $100 \mu L$;

- Temperatura de trabalho do forno: $45^{\circ} \mathrm{C}$;

- Temperatura máxima de trabalho do forno: $50^{\circ} \mathrm{C}$.

Os álcoois foram determinados por meio da análise de headspace no cromatógrafo a gás Shimadzu GC-2010 com módulo AOC-5000, seguindo metodologia desenvolvida no LPB. As condições para as análises cromatográficas foram:

- Coluna capilar: Innowax;

- Temperatura da coluna: $35^{\circ} \mathrm{C}$;

- Temperatura máxima da coluna: $250^{\circ} \mathrm{C}$;

- Temperatura do injetor: $250^{\circ} \mathrm{C}$;

- Fluxo total: $6,1 \mathrm{ml} / \mathrm{min}$;

- Fluxo na coluna: $1,56 \mathrm{ml} / \mathrm{min}$;

- Gás de makeup: Nitrogênio/Ar sintético;

- Volume de amostra injetada: $400 \mu L$;

- Temperatura inicial do forno: $35^{\circ} \mathrm{C}$;

- Temperatura final do forno: $170^{\circ} \mathrm{C}$. 
A quantificação de carboidratos foi realizada pelo método de DUBOIS et al. (1956), que determina a concentração de carboidratos em mg glicose/L.

O volume de hidrogênio produzido pelo reator foi determinado por meio do medidor de gás MilliGas-counter da marca Ritter precedido por um mecanismo de retenção de $\mathrm{CO}_{2}$ do biogás. Este mecanismo consistiu no borbulhamento do biogás em um erlenmeyer contendo uma solução de hidróxido de sódio $(\mathrm{NaOH})$ com concentração de $5 \mathrm{~mol} / \mathrm{l}$.

O desenho esquemático do reator e sua imagem fotográfica são mostrados na Figura 4.1



Figura 4.1: Desenho esquemático do reator (unidade em $\mathrm{mm}$ ) e sua imagem fotográfica Fonte: PEIXOTO (2008).

\subsection{Dados experimentais}

O reator anaeróbio de leito fixo, com volume total de $3,77 \mathrm{~L}$, operado com TDH de $0,5 h$, apresentou o perfil espacial apresentado na Tabela 4.1, segundo PEIXOTO (2008): 
Tabela 4.1: Perfil espacial da concentração de álcoois e ácidos no reator.

\begin{tabular}{c|c|cccc|cc}
\hline \multirow{2}{*}{$\begin{array}{c}\text { Pontos } \\
\text { de }\end{array}$} & Distância & \multicolumn{5}{|c|}{ Ácidos } & \multicolumn{2}{c}{ Álcoois } \\
\cline { 3 - 8 } da Base & Propiônico & Lático & Acético & Butírico & Metanol & Etanol \\
& $c m$ & $m g / L$ & $m g / L$ & $m g / L$ & $m g / L$ & $m g / L$ & $m g / L$ \\
\hline 1 & 3,50 & 206,9 & 22,5 & 12,9 & 8,7 & 20,9 & 20,8 \\
2 & 15,50 & 210,4 & 71,1 & 57,4 & 20,8 & 20,9 & 27,2 \\
3 & 25,25 & 226,9 & 121,6 & 114,8 & n.a. & 21,1 & 46,4 \\
4 & 35,00 & 226,0 & 89,6 & 78,8 & 24,1 & 20,9 & 33,5 \\
5 & 44,75 & 236,6 & 124,9 & 114,1 & 42,2 & 20,9 & 43,5 \\
6 & 54,50 & 239,0 & 154,9 & 157,2 & 59,6 & 24,2 & n.a. \\
7 & 65,50 & 245,7 & 164,4 & 211,9 & 61,0 & 21,2 & 63,1 \\
\hline
\end{tabular}

n.a - não analisada

O ponto 1 refere-se ao ponto de entrada de afluente no reator, os pontos 2, 3, 4,5 e 6 são os pontos de coleta, de baixo para cima, e o ponto 7 é o ponto de saída do efluente, como mostra a Figura 4.2.

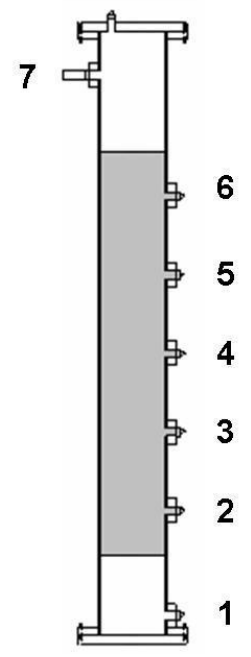

Figura 4.2: Pontos de amostragem do reator

A concentração de glicose quantificada no afluente foi de $1460,9 \mathrm{mg} / \mathrm{L}$ e no efluente, foi de $1077,4 \mathrm{mg} / \mathrm{L}$.

O rendimento da produção de hidrogênio foi de 4,12 mol $H_{2} /$ mol glicose e a vazão molar calculada foi de 41,6 $\mathrm{mmol} H_{2} / h$.

A solubilidade do gás, embora bastante baixa, foi considerada na formulação matemática e é igual a $7,36 \times 10^{-4} \mathrm{~mol} H_{2} / L$.

A concentração de biomassa no leito $\left(C_{x}\right)$ foi considerada constante e igual a 
118,4 g $S S V / L$.

\subsection{Formulação do modelo}

O reator anaeróbio de leito fixo foi dividido em três regiões (elementos de volume) análogas a reatores ideais. A região de mistura (1) e a zona de separação de fases (3) foram comparadas a reatores com mistura perfeita, e o leito foi considerado análogo a um reator tubular ideal, como mostra a Figura 4.3. Estes três reatores trabalham em série para a degradação do afluente. As regiões 1, 2 e 3 possuem, respectivamente, $10 \mathrm{~cm}, 50 \mathrm{~cm}$ e $15 \mathrm{~cm}$.

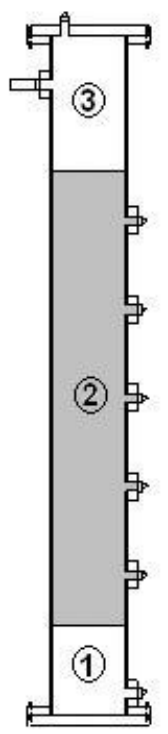

Figura 4.3: Representação do modelo compartimentado, em que as regiões 1 e 3 representam um reator com mistura perfeita e a região 2 , um reator tubular ideal.

Para a simplificação do modelo algumas considerações são previamente postas:

- O sistema é pseudo-homogêneo, isto é, a formulação foi desenvolvida assumindo que as reações ocorrem apenas na fase líquida. Dessa forma, o fator de efetividade $(\eta)$, que é uma medida do quanto o reagente se difunde na partícula antes de ser consumido, é igual a 1, ou seja, não há interferência dos efeitos de transferência de massa; 
- A temperatura e as constantes de velocidade das reações não variam ao longo do reator;

- O reator atingiu o estado estacionário. Não há variação temporal da concentração dos componentes;

- A vazão e a concentração do substrato afluente são constantes;

- Não são considerados os fenômenos de transporte difuso;

- As reações são consideradas elementares.

\subsubsection{Reações envolvidas no processo}

A variação da energia livre de Gibbs, $\Delta G$, é uma propriedade termodinâmica que indica a espontaneidade de uma reação química. Se $\Delta G<0$, a transformação pode ocorrer espontaneamente; se $\Delta G=0$, o sistema está em equilíbrio; e se $\Delta G>0$, a transformação não é espontânea.

Os valores de $\Delta G^{0}$ dos compostos presentes no reator produtor de $H_{2}$ foram retirados do Handbook of Organic Chemistry (DEAN, 1987). São eles:

$$
\begin{gathered}
\Delta G_{\text {glicose }}^{0}=-219,58 \mathrm{kcal} / \mathrm{mol} \\
\Delta G_{\text {acetico }}^{0}=-93,56 \mathrm{kcal} / \mathrm{mol} \\
\Delta G_{\text {butirico }}^{0}=-90,27 \mathrm{kcal} / \mathrm{mol} \\
\Delta G_{\text {propionico }}^{0}=-91,65 \mathrm{kcal} / \mathrm{mol} \\
\Delta G_{\text {latico }}^{0}=-124,98 \mathrm{kcal} / \mathrm{mol} \\
\Delta G_{\text {etanol }}^{0}=-41,63 \mathrm{kcal} / \mathrm{mol} \\
\Delta G_{\text {metanol }}^{0}=-39,87 \mathrm{kcal} / \mathrm{mol} \\
\Delta G_{\mathrm{H}_{2} O}^{0}=-56,69 \mathrm{kcal} / \mathrm{mol}
\end{gathered}
$$




$$
\begin{gathered}
\Delta G_{\mathrm{CO}_{2} \text { liq }}^{0}=-98,69 \mathrm{kcal} / \mathrm{mol} \\
\Delta G_{\mathrm{H}_{2}}^{0}=0 \mathrm{kcal} / \mathrm{mol}
\end{gathered}
$$

A variação da energia livre de Gibbs padrão pode ser obtida por meio da equação:

$$
\Delta G^{0}=\Delta G_{\text {produtos }}^{0}-\Delta G_{\text {reagentes }}^{0}
$$

Desta forma, as reações bioquímicas envolvidas no processo de produção biológica de $\mathrm{H}_{2}$ a partir da glicose, e os respectivos valores de $\Delta G^{0}$ estão representados nas equações 4.1 à 4.10 .

$$
\begin{aligned}
& \mathrm{C}_{6} \mathrm{H}_{12} \mathrm{O}_{6} \stackrel{k_{1}}{\rightarrow} \\
& \text { glicose }
\end{aligned}
$$

$$
\Delta G^{0}=-68,03 \mathrm{kcal} / \mathrm{mol}
$$

$$
\begin{array}{ll}
\mathrm{C}_{6} \mathrm{H}_{12} \mathrm{O}_{6}+2 \mathrm{H}_{2} \mathrm{O} \stackrel{k_{2}}{\rightarrow} & 2 \mathrm{C}_{2} \mathrm{H}_{4} \mathrm{O}_{2}+2 \mathrm{CO}_{2}+4 \mathrm{H}_{2} \\
\text { glicose } & \text { ác. acético }
\end{array}
$$

$$
\begin{array}{cc}
\Delta G^{0}= & -51,54 \mathrm{kcal} / \mathrm{mol} \\
\mathrm{C}_{6} \mathrm{H}_{12} \mathrm{O}_{6}+2 \mathrm{H}_{2} \stackrel{k_{3}}{\rightarrow} 2 \mathrm{C}_{3} \mathrm{H}_{6} \mathrm{O}_{2}+2 \mathrm{H}_{2} \mathrm{O} \\
\text { glicose ác. propiônico } \\
\Delta G^{0}= & -77,10 \mathrm{kcal} / \mathrm{mol}
\end{array}
$$


$\mathrm{C}_{6} \mathrm{H}_{12} \mathrm{O}_{6} \stackrel{k_{4}}{\rightarrow} 2 \mathrm{C}_{3} \mathrm{H}_{6} \mathrm{O}_{3}$

glicose ác. lático

$\Delta G^{0}=-30,38 \mathrm{kcal} / \mathrm{mol}$

$\mathrm{C}_{3} \mathrm{H}_{6} \mathrm{O}_{3}+\mathrm{H}_{2} \stackrel{k_{5}}{\longrightarrow} \mathrm{C}_{3} \mathrm{H}_{6} \mathrm{O}_{2}+\mathrm{H}_{2} \mathrm{O}$

ác. lático

ác. propiônico

$$
\Delta G^{0}=-23,36 \mathrm{kcal} / \mathrm{mol}
$$

$\mathrm{C}_{4} \mathrm{H}_{8} \mathrm{O}_{2}+2 \mathrm{H}_{2} \mathrm{O} \stackrel{k_{6}}{\rightarrow} 2 \mathrm{C}_{2} \mathrm{H}_{4} \mathrm{O}_{2}+2 \mathrm{H}_{2}$

ác. butírico

ác. acético

$$
\Delta G^{0}=+16,53 \mathrm{kcal} / \mathrm{mol}
$$

$$
\mathrm{C}_{3} \mathrm{H}_{6} \mathrm{O}_{2}+2 \mathrm{H}_{2} \mathrm{O} \stackrel{k_{7}}{\rightarrow} \mathrm{C}_{2} \mathrm{H}_{4} \mathrm{O}_{2}+\mathrm{CO}_{2}+3 \mathrm{H}_{2}
$$

ác. propiônico

ác. acético

$$
\Delta G^{0}=+12,78 \mathrm{kcal} / \mathrm{mol}
$$

$\mathrm{C}_{3} \mathrm{H}_{6} \mathrm{O}_{3}+\mathrm{H}_{2} \mathrm{O} \stackrel{k_{8}}{\longrightarrow} \mathrm{C}_{2} \mathrm{H}_{4} \mathrm{O}_{2}+\mathrm{CO}_{2}+2 \mathrm{H}_{2}$

ác. lático

ác. acético

$$
\Delta G^{0}=-10,58 \mathrm{kcal} / \mathrm{mol}
$$




$$
\begin{aligned}
& \mathrm{C}_{6} \mathrm{H}_{12} \mathrm{O}_{6} \stackrel{k_{9}}{\rightarrow} 2 \mathrm{C}_{2} \mathrm{H}_{6} \mathrm{O}+2 \mathrm{CO}_{2} \\
& \text { glicose etanol } \\
& \Delta G^{0}=-61,06 \mathrm{kcal} / \mathrm{mol}
\end{aligned}
$$

Por analogia à reação 4.9, foi considerada a reação de formação do metanol (4.10).

$$
\begin{gathered}
\mathrm{C}_{6} \mathrm{H}_{12} \mathrm{O}_{6}+2 \mathrm{H}_{2} \mathrm{O} \stackrel{k_{10}}{\rightarrow} \underset{\text { glicose }}{4 \mathrm{CH}_{4} \mathrm{O}+2 \mathrm{CO}_{2}} \\
\text { metanol } \\
\Delta G^{0}=-23,90 \mathrm{kcal} / \mathrm{mol}
\end{gathered}
$$

Os índices $k_{1}, k_{2}, k_{4}, k_{6}, k_{7}, k_{8}, k_{9}$ e $k_{10}$, dados em $[L]^{3}[T]^{-1}[M]^{-1} S S V, k_{3}$ em $[L]^{9}[M]^{-2}[M]^{-1} S S V[T]^{-1}$, e $k_{5}$ em $[L]^{6}[M]^{-1}[M]^{-1} S S V[T]^{-1}$, são as constantes de velocidade das reações representadas pelas equações 4.1, 4.2, 4.4, 4.6, 4.7, 4.8, $4.9,4.10,4.3$ e 4.5 , respectivamente.

Embora os valores de $\Delta G^{0}$ sejam positivos nas reações 4.6 e 4.7, estas foram consideradas no desenvolvimento do modelo uma vez que a remoção de alguns produtos (como o $\mathrm{H}_{2}$ ) favorece o deslocamento do equilíbrio químico da reação.

A velocidade de uma reação homogênea $(r)$ pode ser definida como a variação do número de mols ou massa de um reagente ou produto por unidade de tempo e por unidade de volume da mistura de reação. Nas reações consideradas, a velocidade de formação ou de consumo de cada composto foi calculada em função da concentração dos reagentes e seus coeficientes estequiométricos, e da constante de velocidade, como mostram as equações:

-Glicose

$$
\left(r_{g}\right)=-\left(k_{1}+k_{2} C_{H_{2} O}^{2}+k_{4}+k_{9}+k_{10} C_{H_{2} O}^{2}\right) C_{x} C_{g}-k_{3} C_{x} C_{H_{2}}^{2} C_{g}
$$


em que $C_{H_{2} O}, C_{g}$ e $C_{H_{2}}$ são as concentrações de água, glicose e hidrogênio, respectivamente, em $[M][L]^{-3}, C_{x}$ é a concentração de biomassa no reator em termos de $[M] S S V[L]^{-3}$, e $\left(r_{g}\right)$ é a velocidade de consumo da glicose em $[M][L]^{-3}[T]^{-1}$.

A $C_{H_{2} \mathrm{O}}$ é muito maior que as concentrações dos outros reagentes. Portanto, mesmo após o consumo de todas as moléculas de reagentes, a $C_{H_{2} O}$ no final da reação será muito próxima àquela no início. Como a $C_{H_{2} O}$ é praticamente constante, pode-se escrever: $k C_{H_{2} O}=k^{\prime}$. Desta forma, a equação que representa a velocidade de consumo da glicose é:

$$
\left(r_{g}\right)=-\left(k_{1}+k_{2}^{\prime}+k_{4}+k_{9}+k_{10}^{\prime}\right) C_{x} C_{g}-k_{3} C_{x} C_{H_{2}}^{2} C_{g}
$$

Para os demais compostos, os subíndices $e, m, b, l, p, a$ e $H_{2}$ referem-se, respectivamente, ao etanol, metanol, ácido butírico, ácido lático, ácido propiônico, ácido acético e hidrogênio.

-Etanol

$$
\left(r_{e}\right)=k_{9} C_{x} C_{g}
$$

-Metanol

$$
\left(r_{m}\right)=k_{10}^{\prime} C_{x} C_{g}
$$

-Ácido butírico

$$
\left(r_{b}\right)=k_{1} C_{x} C_{g}-k_{6}^{\prime} C_{x} C_{b}
$$

-Ácido lático

$$
\left(r_{l}\right)=C_{x}\left(k_{4} C_{g}-k_{5} C_{l} C_{H_{2}}-k_{8}^{\prime} C_{l}\right)
$$

-Ácido propiônico

$$
\left(r_{p}\right)=C_{x}\left(k_{3} C_{g} C_{H_{2}}^{2}+k_{5} C_{l} C_{H_{2}}-k_{7}^{\prime} C_{p}\right)
$$


-Ácido acético

$$
\left(r_{a}\right)=C_{x}\left(k_{2}^{\prime} C_{g}+k_{6}^{\prime} C_{b}+k_{7}^{\prime} C_{p}+k_{8}^{\prime} C_{l}\right)
$$

-Hidrogênio

$$
\begin{aligned}
\left(r_{H_{2}}\right)= & C_{x}\left[\left(k_{1}+k_{2}^{\prime}\right) C_{g}-k_{3} C_{H_{2}}^{2} C_{g}-k_{5} C_{l} C_{H_{2}}+\right. \\
& \left.k_{6}^{\prime} C_{b}+k_{7}^{\prime} C_{p}+k_{8}^{\prime} C_{l}\right]
\end{aligned}
$$

\subsubsection{Balanço material}

\section{Regiões 1 e 3}

O desenvolvimento do modelo partiu dos balanços de massa e molar em cada elemento de volume do reator, desprezando quaisquer variações radiais na concentração.

O balanço de massa consiste na quantificação dos materiais que entram, saem e se acumulam em um sistema com limites físicos definidos. Este balanço baseiase na lei de conservação de massa, em que nada é criado ou destruído, e sim transformado.

A expressão do balanço de massa é desenvolvida sobre um volume de controle fechado e possui termos para a entrada, saída, geração ou consumo, e acumulação de materiais dentro do volume em que as reações se processam. O balanço de massa geral para o reator com mistura perfeita, que se refere às regiões 1 e 3 , é mostrado a seguir:

$$
Q C_{i_{0}}-Q C_{i} \pm\left(r_{i}\right) V=V \frac{\partial C_{i}}{\partial t}
$$

$C_{i}$ e $C_{i_{0}}$, em $[M][L]^{-3}$, são as concentrações de saída e de entrada, respectivamente, de um certo composto no reator, $Q$, em $[L]^{3}[T]^{-1}$, é a vazão e $V$, em $[L]^{3}$, é o volume do reator.

Considerando o sistema em regime permanente, ou seja, $\frac{\partial C_{i}}{\partial t}=0$, tem-se: 


$$
\begin{aligned}
& \pm\left(r_{i}\right)=\frac{Q}{V}\left(C_{i}-C_{i_{0}}\right) \\
& \pm\left(r_{i}\right)=\frac{1}{\theta_{h}}\left(C_{i}-C_{i_{0}}\right)
\end{aligned}
$$

em que $\theta_{h}$, em [T], é o tempo de detenção hidráulica.

Este balanço é válido para os compostos presentes no reator anaeróbio de leito fixo, com exceção do hidrogênio, diferindo apenas no termo reacional. As velocidades das reações bioquímicas calculadas no item anterior foram substituídas na equação 4.22 para cada caso particular, obtendo-se o balanço de massa para a glicose, os álcoois e os ácidos, como mostram as equações 4.23 à 4.36:

-Glicose

$$
\begin{gathered}
-\left(k_{1}+k_{2}^{\prime}+k_{4}+k_{9}+k_{10}^{\prime}\right) C_{x} C_{g}-k_{3} C_{x} C_{H_{2}}^{2} C_{g}=\frac{1}{\theta_{h}}\left(C_{g}-C_{g_{0}}\right) \\
C_{g}=\frac{C_{g_{0}}}{C_{x} \theta_{h}\left(k_{1}+k_{2}^{\prime}+k_{4}+k_{9}+k_{10}^{\prime}+k_{3} C_{H_{2}}^{2}\right)+1}
\end{gathered}
$$

-Etanol

$$
\begin{gathered}
k_{9} C_{x} C_{g}=\frac{1}{\theta_{h}}\left(C_{e}-C_{e_{0}}\right) \\
C_{e}=C_{e_{0}}+k_{9} C_{x} C_{g} \theta_{h}
\end{gathered}
$$

-Metanol

$$
\begin{gathered}
k_{10}^{\prime} C_{x} C_{g}=\frac{1}{\theta_{h}}\left(C_{m}-C_{m_{0}}\right) \\
C_{m}=C_{m_{0}}+k_{10}^{\prime} C_{x} C_{g} \theta_{h}
\end{gathered}
$$

-Ácido butírico

$$
\begin{gathered}
k_{1} C_{x} C_{g}-k_{6}^{\prime} C_{x} C_{b}=\frac{1}{\theta_{h}}\left(C_{b}-C_{b_{0}}\right) \\
C_{b}=\frac{C_{b_{0}}+k_{1} C_{x} \theta_{h} C_{g}}{k_{6}^{\prime} C_{x} \theta_{h}+1}
\end{gathered}
$$


-Ácido lático

$$
\begin{gathered}
C_{x}\left(k_{4} C_{g}-k_{5} C_{l} C_{H_{2}}-k_{8}^{\prime} C_{l}\right)=\frac{1}{\theta_{h}}\left(C_{l}-C_{l_{0}}\right) \\
C_{l}=\frac{C_{l_{0}}+k_{4} C_{x} C_{g} \theta_{h}}{1+C_{x} \theta_{h}\left(k_{5} C_{H_{2}}+k_{8}^{\prime}\right)}
\end{gathered}
$$

-Ácido propiônico

$$
\begin{gathered}
C_{x}\left(k_{3} C_{g} C_{H_{2}}^{2}+k_{5} C_{l} C_{H_{2}}-k_{7}^{\prime} C_{p}\right)=\frac{1}{\theta_{h}}\left(C_{p}-C_{p_{0}}\right) \\
C_{p}=\frac{C_{x} \theta_{h}\left(k_{3} C_{g} C_{H_{2}}^{2}+k_{5} C_{l} C_{H_{2}}\right)+C_{p_{0}}}{k_{7}^{\prime} \theta_{h} C_{x}+1}
\end{gathered}
$$

-Ácido acético

$$
\begin{gathered}
C_{x}\left(k_{2}^{\prime} C_{g}+k_{6}^{\prime} C_{b}+k_{7}^{\prime} C_{p}+k_{8}^{\prime} C_{l}\right)=\frac{1}{\theta_{h}}\left(C_{a}-C_{a_{0}}\right) \\
C_{a}=C_{a_{0}}+\theta_{h} C_{x}\left(k_{2}^{\prime} C_{g}+k_{6}^{\prime} C_{b}+k_{7}^{\prime} C_{p}+k_{8}^{\prime} C_{l}\right)
\end{gathered}
$$

Para a quantificação de hidrogênio no elemento de volume, por conveniência, optou-se trabalhar com vazões molares. Desta forma, o balanço molar para o hidrogênio é:

$$
F_{0\left(H_{2}\right)}-F_{\left(H_{2}\right)}+\left(r_{H_{2}}\right)_{N} V-Q s=\frac{\partial N_{H_{2}}}{\partial t}
$$

Considerando o sistema em regime permanente, tem-se:

$$
F_{\left(H_{2}\right)}=F_{0\left(H_{2}\right)}+\left(r_{H_{2}}\right)_{N} V-Q s
$$

$F_{0\left(H_{2}\right)}$ e $F_{\left(H_{2}\right)}$ são, respectivamente, as vazões molares de hidrogênio na saída e na entrada do elemento de volume em $[N][T]^{-1} ; s$ é a solubilidade do hidrogênio em água em $[L]^{3}[L]^{-3}$; e $\left(r_{H_{2}}\right)_{N}$ é a velocidade de formação do hidrogênio em $[N][L]^{-3}[T]^{-1}$.

A vazão molar do $H_{2}$ é representada pelo produto entre a vazão do gás no 
sistema e a sua concentração. Desta forma, é conveniente que a $\left(r_{H_{2}}\right)$ e a $\left(r_{H_{2}}\right)_{N}$ não sejam uma função de $C_{H_{2}}$.

Na reação 4.3, a relação estequiométrica entre a glicose e o $H_{2}$ resultou em $C_{H_{2}}=\frac{C_{g}}{45}$. Da mesma forma, em 4.5, a relação entre o ácido lático e o $H_{2}$ resultou em $C_{H_{2}}=\frac{C_{l}}{45}$. Portanto, a velocidade de formação do gás pode ser escrita como:

$$
\left(r_{H_{2}}\right)=C_{x}\left[\left(k_{1}+k_{2}^{\prime}\right) C_{g}-k_{3} \frac{C_{g}^{3}}{45^{2}}-k_{5} \frac{C_{l}^{2}}{45}+k_{6}^{\prime} C_{b}+k_{7}^{\prime} C_{p}+k_{8}^{\prime} C_{l}\right]
$$

A $\left(r_{H_{2}}\right)_{N}$ é igual a relação entre $\left(r_{H_{2}}\right)$ e a massa molar do $H_{2}\left(M M_{H_{2}}\right)$. Logo:

$$
\begin{gathered}
F_{\left(H_{2}\right)=} F_{0\left(H_{2}\right)}+V \frac{C_{x}}{M M_{H_{2}}}\left[\left(k_{1}+k_{2}^{\prime}\right) C_{g}-k_{3} \frac{C_{g}^{3}}{45^{2}}-\right. \\
\left.k_{5} \frac{C_{l}^{2}}{45}+k_{6}^{\prime} C_{b}+k_{7}^{\prime} C_{p}+k_{8}^{\prime} C_{l}\right]-Q s
\end{gathered}
$$

\section{Região 2}

No caso do reator tubular ideal, região 2, o balanço de massa foi feito para um elemento de volume diferencial $(\partial V)$ :

$$
w_{i_{0}}-\left(w_{i_{0}}+\partial w_{i}\right) \pm\left(r_{i}\right) \partial V=V \frac{\partial C_{i}}{\partial t}
$$

Considerando $\frac{\partial C_{i}}{\partial t}=0$ obtém-se o balanço de massa geral representado pela seguinte equação:

$$
\pm\left(r_{i}\right)=Q \frac{\partial C_{i}}{\partial V}
$$

Conforme feito anteriormente, substitui-se a velocidade das reações na equação 4.42 para cada componente, obtendo-se o balanço de massa para a glicose, os álcoois e os ácidos, como mostram as equações 4.43 à 4.48 :

-Glicose

$$
C_{g}=\frac{C_{g_{0}}}{e^{\theta_{h} C_{x}\left(k_{1}+k_{2}^{\prime}+k_{4}+k_{9}+k_{10}^{\prime}+k_{3} C_{H_{2}}^{2}\right)}}
$$


-Etanol

$$
C_{e}=C_{e_{0}}+k_{9} C_{x} C_{g} \theta h
$$

-Metanol

$$
C_{m}=C_{m_{0}}+k_{10}^{\prime} C_{x} C_{g} \theta h
$$

-Ácido butírico

$$
C_{b}=\frac{C_{b_{0}}}{e^{k_{6}^{\prime} C x \theta_{h}}}+\frac{k_{1} C_{g}}{k_{6}^{\prime}}\left(1-\frac{1}{e^{k_{6}^{\prime} C x \theta_{h}}}\right)
$$

-Ácido lático

$$
C_{l}=\frac{k_{4} C_{g}}{k_{5} C_{H_{2}}+k_{8}^{\prime}}+\frac{1}{e^{\theta_{h} C_{x}\left(k_{5} C_{H_{2}}+k_{8}^{\prime}\right)}}\left(C_{l_{0}}+\frac{k_{4} C_{g}}{k_{5} C_{H_{2}}+k_{8}^{\prime}}\right)
$$

-Ácido propiônico

$$
\begin{aligned}
C_{p}= & \frac{1}{k_{7}^{\prime}}\left[k_{3} C_{g} C_{H_{2}}^{2}+k_{5} C_{l} C_{H_{2}}+\frac{1}{e^{\theta_{h} C_{x} k_{7}^{\prime}}}\left(k_{7}^{\prime} C_{p_{0}}+\right.\right. \\
& \left.\left.k_{3} C_{g} C_{H_{2}}^{2}+k_{5} C_{l} C_{H_{2}}\right)\right]
\end{aligned}
$$

-Ácido acético

$$
C_{a}=C_{a_{0}}+\theta_{h} C_{x}\left(k_{2}^{\prime} C_{g}+k_{6}^{\prime} C_{b}+k_{7}^{\prime} C_{p}+k_{8}^{\prime} C_{l}\right)
$$

Para o hidrogênio, o balanço molar em um elemento de volume é:

$$
F_{0\left(H_{2}\right)}-\left[F_{0\left(H_{2}\right)}+\partial F_{\left(H_{2}\right)}\right]+\left(r_{H_{2}}\right) V-Q s=\frac{\partial N_{H_{2}}}{\partial t}
$$

Considerando o sistema em regime permanente e integrando $\partial F_{\left(H_{2}\right)}$ no intervalo compreendido entre $F_{0\left(H_{2}\right)}$ e $F_{\left(H_{2}\right)}$, tem-se:

$$
F_{\left(H_{2}\right)}=F_{0\left(H_{2}\right)}+\left(r_{H_{2}}\right)_{N} V-Q s
$$


Substituindo $\left(r_{H_{2}}\right)_{N}$ por $\left(r_{H_{2}}\right) / M M_{H_{2}}$ :

$$
\begin{aligned}
F_{\left(H_{2}\right)}= & F_{0\left(H_{2}\right)}+V \frac{C_{x}}{M M_{H_{2}}}\left[\left(k_{1}+k_{2}^{\prime}\right) C_{g}-k_{3} \frac{C_{g}^{3}}{45^{2}}-\right. \\
& \left.k_{5} \frac{C_{l}^{2}}{45}+k_{6}^{\prime} C_{b}+k_{7}^{\prime} C_{p}+k_{8}^{\prime} C_{l}\right]-Q s
\end{aligned}
$$

\subsection{Metodologia de resolução}

O modelo apresentado é composto por 8 equações matemáticas e 10 parâmetros de ajuste, formando um sistema possível e indeterminado com infinitas soluções. Dessa forma, optou-se pela determinação de um intervalo de dados para cada parâmetro, em que qualquer valor dentro deste intervalo seja capaz de responder satisfatoriamente ao modelo.

A geração e a análise de diversas combinações de números aleatórios possibilita essa determinação. Para a geração aleatória das constantes de velocidade das reações foi utilizada a distribuição de freqüência uniforme. Nesta distribuição, os valores variam dentro de uma faixa situada entre o valor mínimo e o valor máximo, com igual probabilidade de ocorrência em qualquer valor dentro da faixa.

Como valor máximo, foi adotado o valor da constante de velocidade da reação de conversão da matéria orgânica carbonácea em condições anaeróbias. Esta reação é mostrada na equação 4.53 :

$$
\mathrm{C}_{6} \mathrm{H}_{12} \mathrm{O}_{6}+2 \mathrm{H}_{2} \mathrm{O} \stackrel{k}{\rightarrow} 3 \mathrm{CH}_{4}+3 \mathrm{CO}_{2}
$$

ZAIAT et al. (1997) utilizaram um reator diferencial preenchido com matrizes de espuma de poliuretano contendo biomassa anaeróbia imobilizada para a obtenção da velocidade específica de utilização do substrato $\left(r^{\prime}\right)$. O substrato, composto principalmente por glicose, foi mantido a $30^{\circ} \mathrm{C}$. A metodologia utilizada resultou em velocidade específica máxima de utilização do substrato $\left(r_{\max }^{\prime}\right)$ igual a 0,33 mgDQO $\mathrm{mg}^{-1} S S V h^{-1}$, e em constante de saturação do substrato $\left(K_{s}\right)$ igual a $72 \mathrm{mgDQO} \mathrm{L}^{-1}$. 
De acordo com estes dados, a constante de velocidade da reação global do metabolismo anaeróbio (4.53) é igual a $k=0,33 / 72=4,58 \times 10^{-3} L h^{-1}$ $m g^{-1} S S V$.

Utilizando como ferramenta o Microsoft Office Excel ${ }^{\circledR}$, a geração de variáveis aleatórias pode ser feita por meio das janelas: Ferramentas - Análise de dados Geração de $\mathrm{n}^{\text {os }}$ aleatórios. A janela de interesse é mostrada na Figura 4.4.

Foram geradas 20.000 combinações de parâmetros (10 colunas e 20.000 linhas) variando entre zero e $4,58 \times 10^{-3} \mathrm{~L} \mathrm{~h}^{-1} \mathrm{mg}^{-1} S S V$. A semente aleatória igual a 1 indica que os valores devem ser gerados apenas uma vez.

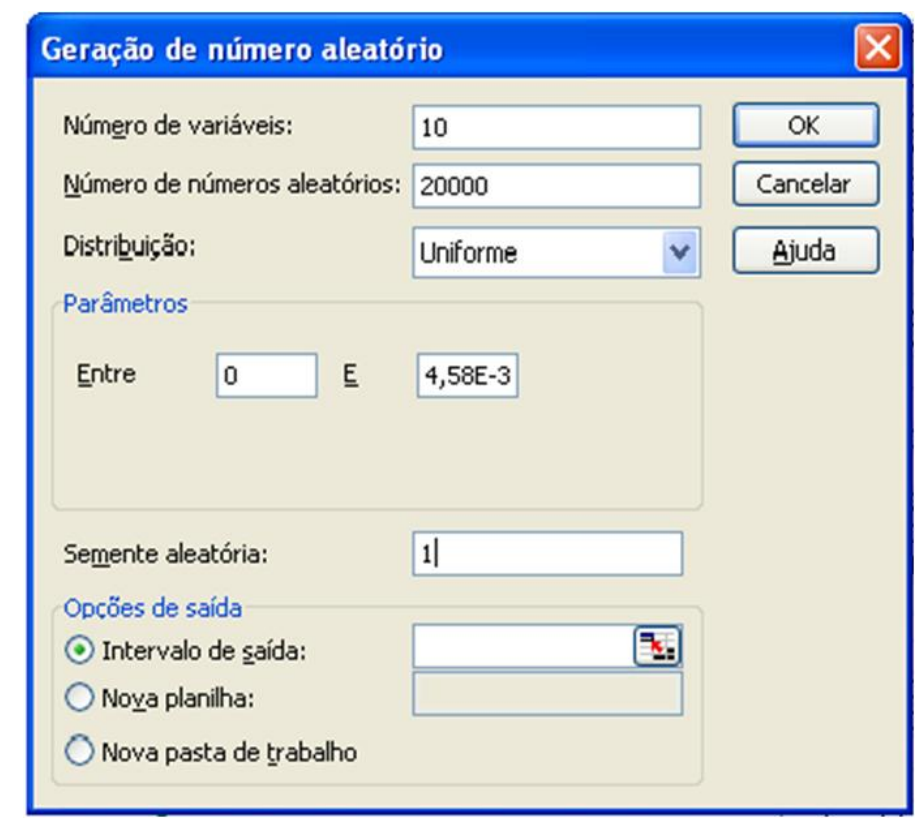

Figura 4.4: Desenho esquemático do reator (unidade em $\mathrm{mm}$ ) e sua imagem

Nas colunas adjacentes são implementadas as condições de contorno para a adequação dos parâmetros, ou seja, as equações do modelo.

As equações do modelo são interdependentes. Para evitar a ciclicidade, buscouse alterar a equação de velocidade da reação 4.3 , de modo que se torne apenas função de $C_{g}$. Para tal, o termo $C_{H_{2}}$ foi relacionado estequiometricamente com $C_{g}$ na reação em questão, e substituído por $C_{g} / 45$.

A equação resultante do novo balanço de massa para glicose na região 2 é mostrada em 4.54. Para a simplificação e apenas nesta etapa, a equação cúbica 
resultante do balanço da glicose para as regiões 1 e 3 foi aproximada por uma função quadrática, indicada em 4.55, utilizando o método dos mínimos quadrados.

$$
\begin{gathered}
C_{g}=\frac{45 C_{g_{0}} \sqrt{k_{1}+k_{2}^{\prime} k_{4}+k_{9}+k_{10}^{\prime}}}{\sqrt{-k_{3} C_{g_{0}}^{2}+e^{2 \theta_{h} C_{x}\left(k_{1}+k_{2}^{\prime} k_{4}+k_{9}+k_{10}^{\prime}\right)\left[45^{2}\left(k_{1}+k_{2}^{\prime} k_{4}+k_{9}+k_{10}^{\prime}\right)+k_{3} C_{g_{0}}^{2}\right]}}} \\
C_{g}=17-\frac{k_{1}+k_{2}^{\prime} k_{4}+k_{9}+k_{10}^{\prime}}{0,15 k_{3}}+\frac{-1+\sqrt{\Delta}}{0,15 \theta_{h} C_{x} k_{3}} \\
\Delta=\theta_{h}^{2} C_{x}^{2}\left[5,71 k_{3}^{2}+\left(k_{1}+k_{2}^{\prime} k_{4}+k_{9}+k_{10}^{\prime}\right)\left(1-5,08 k_{3}\right)\right]+ \\
\theta_{h} C_{x}\left[2\left(k_{1}+k_{2}^{\prime} k_{4}+k_{9}+k_{10}^{\prime}\right)+k_{3}\left(5,08-0,3 C_{g_{0}}\right)\right]+1
\end{gathered}
$$

De acordo com a análise das concentrações de ácidos, álcoois, hidrogênio e glicose obtidas pela resposta aos coeficientes do modelo, foram realizadas diversas rodagens de números aleatórios, buscando reduzir o intervalo de cada coeficiente e aumentar o número de combinações satisfatórias. Foi utilizada uma margem de $\pm 20 \%$ de erro com relação as dados experimentais para uma primeira estimativa.

Nos intervalos obtidos, as concentrações de álcoois e ácidos podem ser facilmente ajustados aos valores experimentais. O mesmo não ocorre com a concentração de glicose e a vazão molar de hidrogênio. Desta forma, buscou-se o conjunto de valores, pertencente aos intervalos encontrados, que produziu os menores desvios no ajuste aos dados experimentais de hidrogênio e de glicose.

Para as constantes de velocidade das reações obtidas, foi realizada uma análise de sensibilidade. Por meio dela, é inferido se a resposta do modelo é pouco ou muito influenciada pelo valor de uma dada variável, o que permite concluir sobre a necessidade de menores ou maiores esforços na obtenção mais precisa de seu valor.

A análise de sensibilidade informal de um dado consiste em execuções consecutivas do programa representativo do modelo com diferentes valores do dado 
em questão e na interpretação dos resultados do modelo a esta variação. Para esta análise, as constantes de velocidade foram analisadas isoladamente com uma variação de $\pm 20 \%$.

Para a obtenção de valores mais precisos, foram fixados os dois parâmetros menos sensíveis e o sistema formado pelas equações do modelo (8 equações matemáticas e 8 parâmetros) foi calculado por meio do método de inversão de matrizes.

A calibração foi realizada manualmente variando-se os valores dos parâmetros de forma que a soma dos quadrados dos resíduos diminuísse até a obtenção um ajuste satisfatório.

Um fluxograma simplificado da sequência de desenvolvimento do modelo matemático é apresentado na Figura 4.5.

O Microsoft Office Excel ${ }^{\circledR}$ foi utilizado como ferramenta para as etapas de implementação computacional, análise de sensibilidade, calibração e análise dos modelos. 


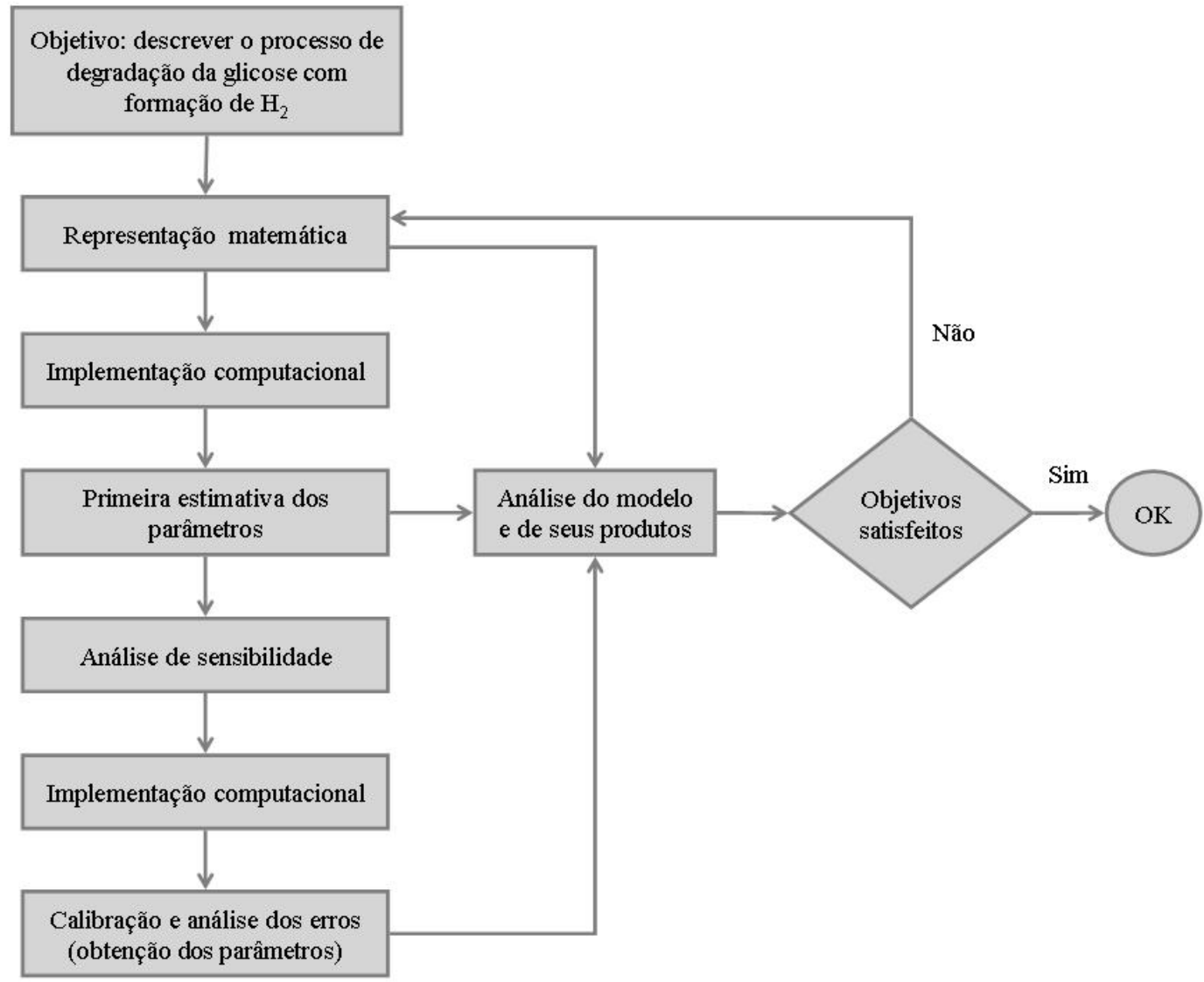

Figura 4.5: Fluxograma das etapas de desenvolvimento do modelo. 


\section{Capítulo 5}

\section{Resultados}

\subsection{Constantes cinéticas}

Os parâmetros de ajuste foram obtidos de modo a obter o menor desvio mínimo quadrado global entre as curvas produzidas pelo modelo compartimentado e os dados experimentais. O valor dos parâmetros são mostrados a seguir:

$$
\begin{aligned}
& k_{1}=8,5210^{-7} L m g S S V^{-1} h^{-1} \\
& k_{2}^{\prime}=4,9210^{-9} L m g S S V^{-1} h^{-1} \\
& k_{3}=3,3010^{-9} L^{3} m^{-2} m g S S V^{-1} h^{-1} \\
& k_{4}=3,8810^{-6} L m g S S V^{-1} h^{-1} \\
& k_{5}=6,4210^{-6} L^{2} m g^{-1} m g S S V^{-1} h^{-1} \\
& k_{6}^{\prime}=9,8910^{-12} L m g S S V^{-1} h^{-1} \\
& k_{7}^{\prime}=1,7010^{-5} L_{m g S S V}^{-1} h^{-1} \\
& k_{8}^{\prime}=1,0810^{-9} L m g S S V^{-1} h^{-1} \\
& k_{9}=6,5810^{-7} \mathrm{~L} \mathrm{mgSSV}^{-1} h^{-1} \\
& k_{10}^{\prime}=1,7610^{-8} \mathrm{~L} \mathrm{mgSSV}^{-1} h^{-1}
\end{aligned}
$$




\subsection{Ajuste do modelo}

Na representação gráfica dos resultados obtidos pelo modelo utiliza-se uma curva com linha contínua enquanto que na representação dos dados experimentais utiliza-se apenas marcadores.

Os perfis de concentrações de ácidos propiônico e acético, e ácidos lático e butírico gerados pelo modelo ao longo do reator e os respectivos valores experimentais são mostrados nas Figuras 5.1 e 5.2 .

O perfil espacial de concentração de álcoois reproduzido pelo modelo e seus dados experimentais são mostrados na Figura 5.3.

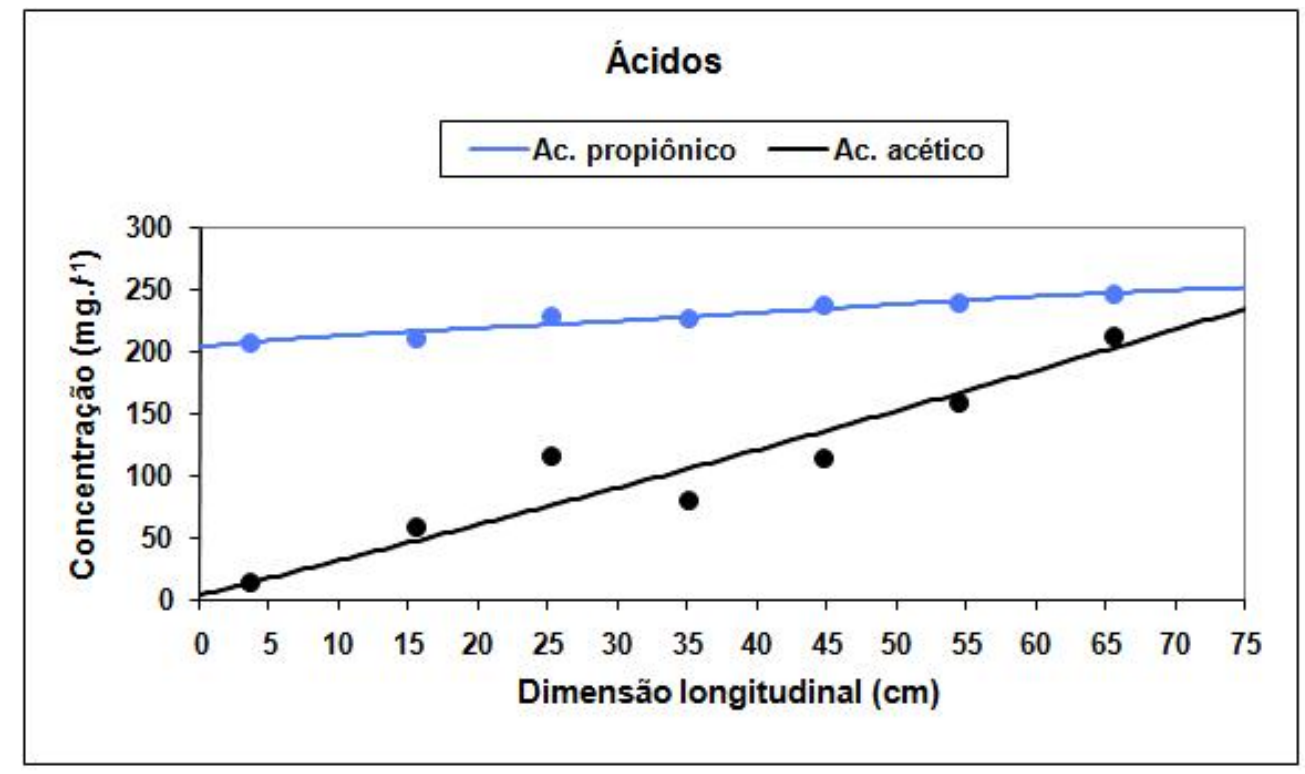

Figura 5.1: Perfil de concentrações de ácidos propiônico e acético. 




Figura 5.2: Perfil de concentrações de ácidos lático e butírico.

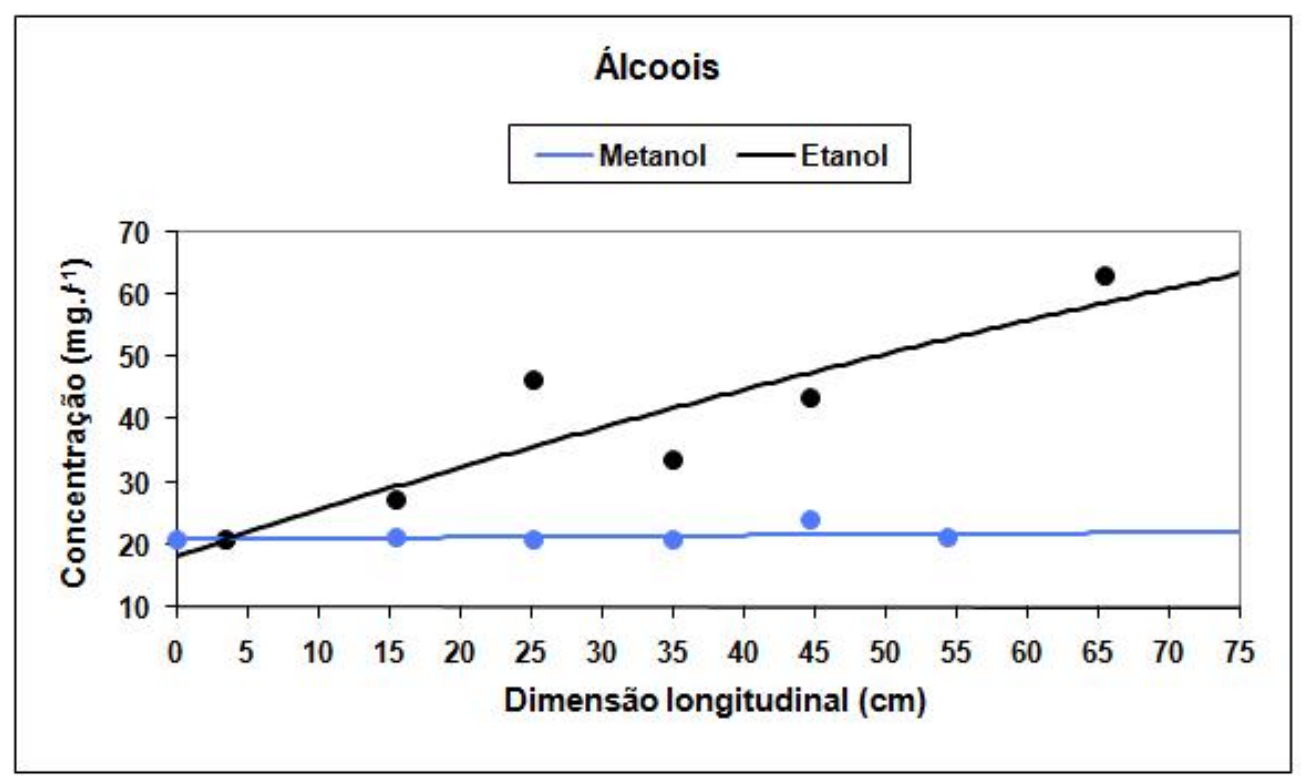

Figura 5.3: Perfil de concentrações de álcoois.

O modelo se ajustou muito bem aos dados experimentais de ácidos e álcoois produzidos no trabalho de PEIXOTO (2008).

A Figura 5.4 fornece o perfil da concentração de glicose ao longo do reator. A concentração efluente de glicose medida no reator foi de $1077,4 \mathrm{mg} \mathrm{L}^{-1}$ enquanto o valor fornecido pelo modelo foi de $980,4 \mathrm{mgL}^{-1}$. O ajuste é razoável, embora a disponibilidade de apenas dois pontos de medições da concentração da glicose 
(afluente e efluente) torne o modelo pouco representativo para a previsão deste carboidrato. Deve-se considerar também a possível dificuldade encontrada na quantificação da glicose devido ao arraste dos sólidos com o efluente.



Figura 5.4: Perfil de concentração de glicose.

A vazão molar de $H_{2}$ gerada no reator é mostrada na Figura 5.5. Nota-se que o gás começa a ser produzido após $9 \mathrm{~cm}$ do início do reator. O valor teórico da vazão molar de $H_{2}$ medido na saída do reator é igual a 41,6 $\mathrm{mmolH}_{2} \mathrm{~h}^{-1} \mathrm{e}$ também igual àquele gerado pelo modelo.

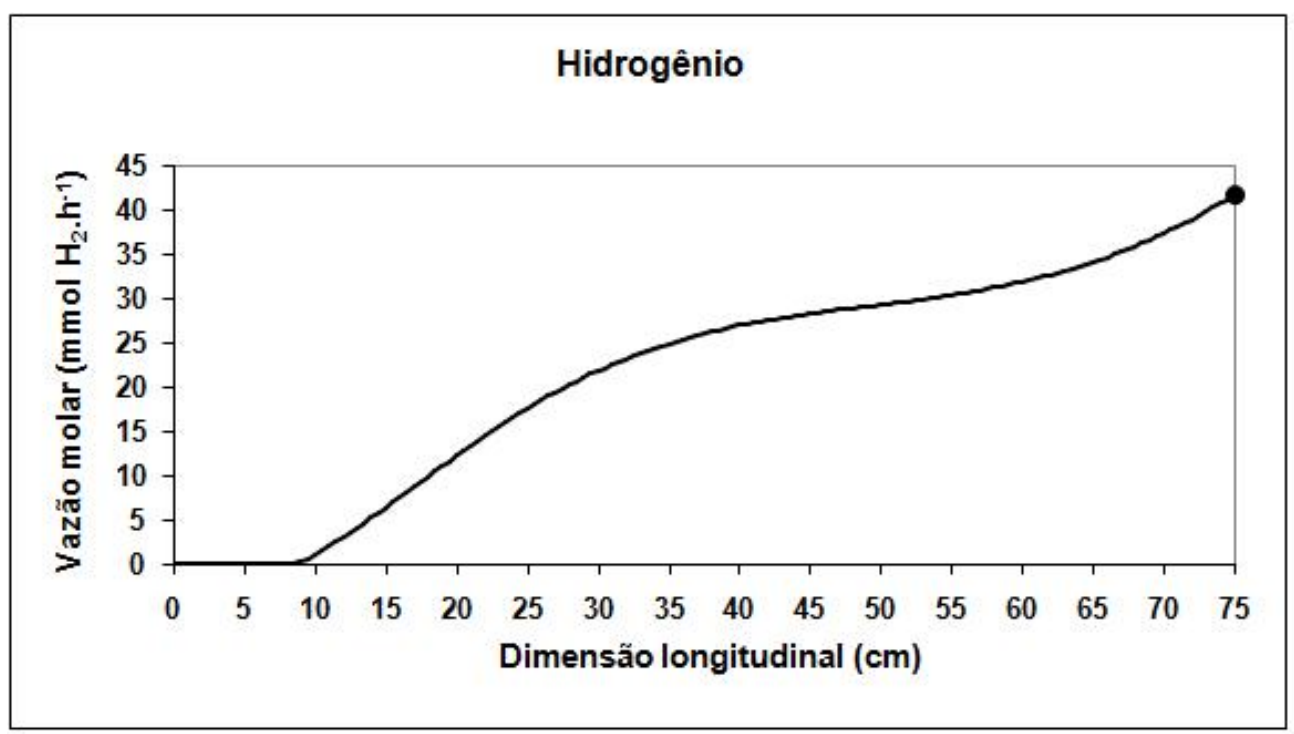

Figura 5.5: Perfil de vazão molar de hidrogênio. 


\subsection{Rotas de formação de $H_{2}$}

A análise informal de sensibilidade verificou a resposta do modelo diante de uma variação de $\pm 20 \%$ em cada constante de velocidade. A maior perturbação nas curvas foi provocada pela alteração de $k_{4}$, embora a sensibilidade de $k_{3}$ seja considerável. A curva da vazão molar de $H_{2}$ foi a mais influenciada devido, principalmente, à sua escala. As Figuras 5.6 e 5.7 mostram o comportamento desta curva quando há variação de $+20 \%$ e de $-20 \%$, respectivamente, no valor de $k_{4}$.

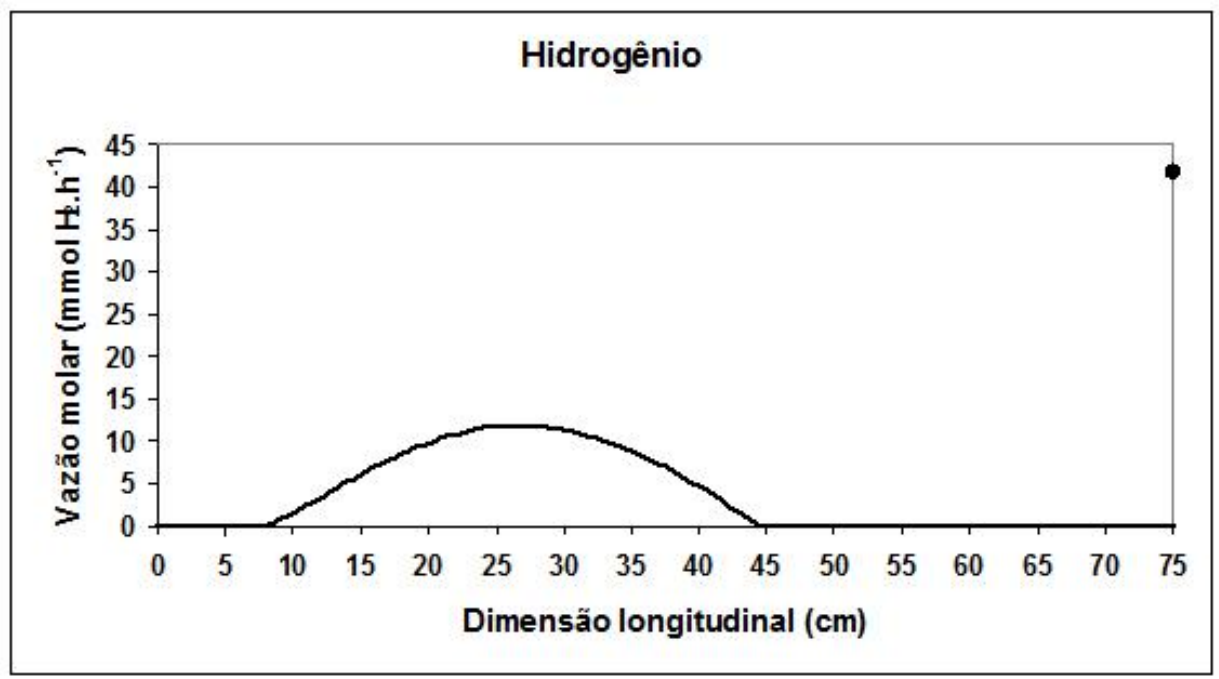

Figura 5.6: Resposta do modelo à variação de $+20 \%$ em $k_{4}$.



Figura 5.7: Resposta do modelo à variação de $-20 \%$ em $k_{4}$. 
As constantes de velocidade menos sensíveis no modelo são $k_{2}^{\prime}, k_{6}^{\prime}$ e $k_{8}^{\prime}$. Isto pode ser justificado uma vez que as velocidades das reações, às quais estas constantes se referem, representadas por R 4.2, R 4.6 e R 4.8 são desprezíveis em relação às velocidades das demais reações. A velocidade destas reações e da reação 4.10, ou seja, R 4.10 estão indicadas na Figura 5.8.

$$
\begin{gathered}
\mathrm{C}_{6} \mathrm{H}_{12} \mathrm{O}_{6}+2 \mathrm{H}_{2} \mathrm{O} \stackrel{k_{2}}{\rightarrow} 2 \mathrm{C}_{2} \mathrm{H}_{4} \mathrm{O}_{2}+2 \mathrm{CO}_{2}+4 \mathrm{H}_{2} \\
\mathrm{C}_{4} \mathrm{H}_{8} \mathrm{O}_{2}+2 \mathrm{H}_{2} \mathrm{O} \stackrel{k_{6}}{\rightarrow} 2 \mathrm{C}_{2} \mathrm{H}_{4} \mathrm{O}_{2}+2 \mathrm{H}_{2} \\
\mathrm{C}_{3} \mathrm{H}_{6} \mathrm{O}_{3}+\mathrm{H}_{2} \mathrm{O} \stackrel{k_{8}}{\rightarrow} \mathrm{C}_{2} \mathrm{H}_{4} \mathrm{O}_{2}+\mathrm{CO}_{2}+2 \mathrm{H}_{2} \\
\mathrm{C}_{6} \mathrm{H}_{12} \mathrm{O}_{6}+2 \mathrm{H}_{2} \mathrm{O} \stackrel{k_{10}}{\rightarrow} 4 \mathrm{CH}_{4} \mathrm{O}+2 \mathrm{CO}_{2}
\end{gathered}
$$

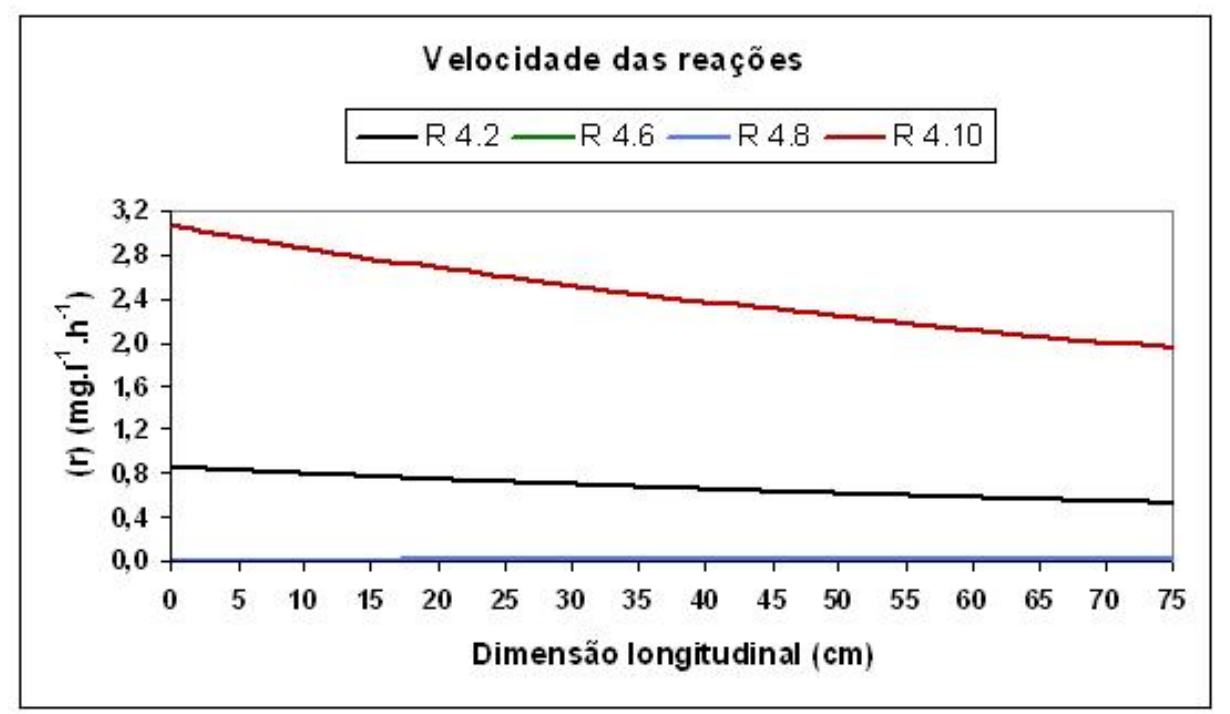

Figura 5.8: Velocidade das reações 4.2, 4.6, 4.8 e 4.10 ao longo do reator.

As reações 4.4, 4.5 e 4.7 se processam rapidamente no sistema. As velocidades destas reações são representadas por $\mathrm{R} 4.4$, R 4.5 e R 4.7, respectivamente, conforme mostrado na Figura 5.9. As velocidades de 4.1, 4.3 e 4.9 são representadas por R 4.1, R 4.3 e R 4.9 e estão indicadas na Figura 5.10.

$$
\begin{gathered}
\mathrm{C}_{6} \mathrm{H}_{12} \mathrm{O}_{6} \stackrel{k_{4}}{\rightarrow} 2 \mathrm{C}_{3} \mathrm{H}_{6} \mathrm{O}_{3} \\
\mathrm{C}_{3} \mathrm{H}_{6} \mathrm{O}_{3}+\mathrm{H}_{2} \stackrel{k_{5}}{\rightarrow} \mathrm{C}_{3} \mathrm{H}_{6} \mathrm{O}_{2}+\mathrm{H}_{2} \mathrm{O} \\
\mathrm{C}_{3} \mathrm{H}_{6} \mathrm{O}_{2}+2 \mathrm{H}_{2} \mathrm{O} \stackrel{k_{7}}{\longrightarrow} \mathrm{C}_{2} \mathrm{H}_{4} \mathrm{O}_{2}+\mathrm{CO}_{2}+3 \mathrm{H}_{2}
\end{gathered}
$$






Figura 5.9: Velocidade das reações $4.4,4.5$ e 4.7 ao longo do reator.

$$
\begin{gathered}
\mathrm{C}_{6} \mathrm{H}_{12} \mathrm{O}_{6} \stackrel{k_{1}}{\rightarrow} \mathrm{C}_{4} \mathrm{H}_{8} \mathrm{O}_{2}+2 \mathrm{CO}_{2}+2 \mathrm{H}_{2} \\
\mathrm{C}_{6} \mathrm{H}_{12} \mathrm{O}_{6}+2 \mathrm{H}_{2} \stackrel{k_{3}}{\longrightarrow} 2 \mathrm{C}_{3} \mathrm{H}_{6} \mathrm{O}_{2}+2 \mathrm{H}_{2} \mathrm{O} \\
\mathrm{C}_{6} \mathrm{H}_{12} \mathrm{O}_{6} \stackrel{k_{9}}{\rightarrow} 2 \mathrm{C}_{2} \mathrm{H}_{6} \mathrm{O}+2 \mathrm{CO}_{2}
\end{gathered}
$$

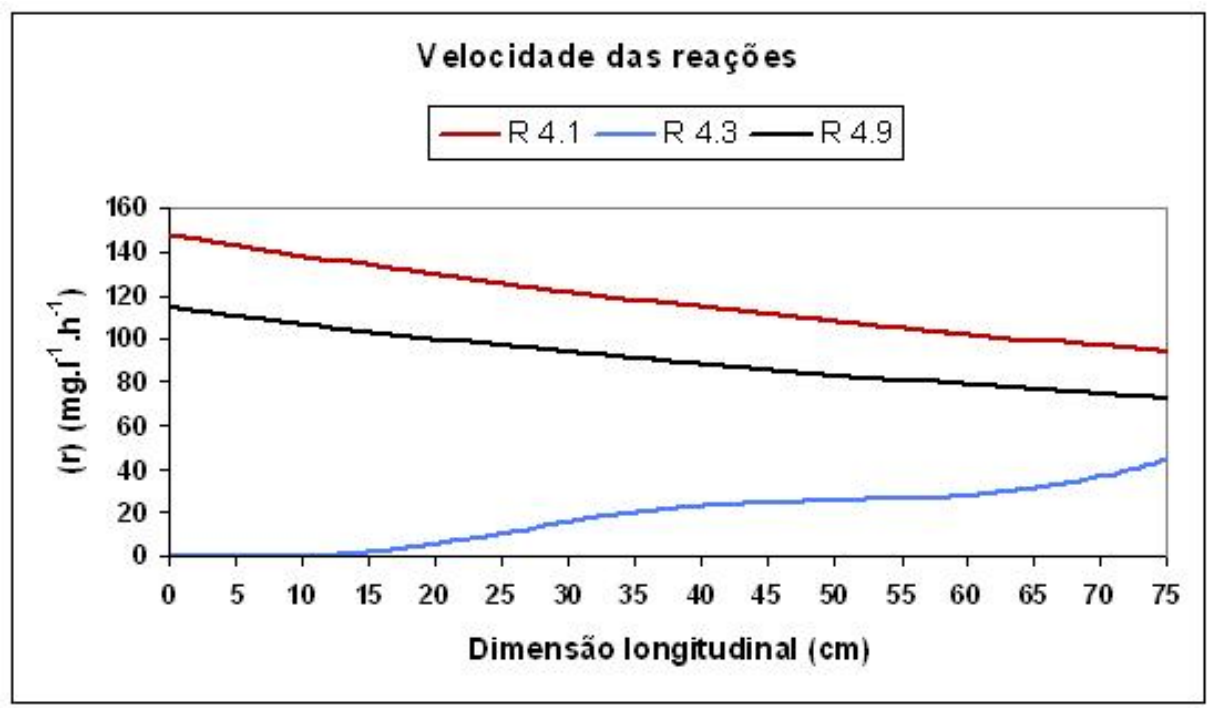

Figura 5.10: Velocidade das reações 4.1, 4.3 e 4.9 ao longo do reator.

Algumas relações entre as velocidades de consumo da glicose ( $\mathrm{R} 4.1, \mathrm{R}$ 4.2, $\mathrm{R} 4.3, \mathrm{R} 4.4, \mathrm{R} 4.9$ e $\mathrm{R} 4.10$ ) em diferentes pontos do reator são mostradas na Tabela 5.1. 
Tabela 5.1: Relações entre as velocidades das reações de consumo de glicose.

\begin{tabular}{cccccc}
\hline Relação & \multicolumn{5}{c}{ Espaço (cm) } \\
\cline { 2 - 6 } & 5 & 20 & 35 & 55 & 70 \\
\hline R 4.3 / R 4.1 & 0,00 & 0,04 & 0,17 & 0,25 & 0,38 \\
R 4.1 / R 4.9 & 1,30 & 1,30 & 1,30 & 1,30 & 1,30 \\
R 4.4 / R 4.1 & 4,56 & 4,56 & 4,56 & 4,56 & 4,56 \\
R 4.3 / R 4.2 & 0,00 & 6,99 & 29,10 & 43,34 & 65,53 \\
R 4.10 / R 4.2 & 3,59 & 3,59 & 3,59 & 3,59 & 3,59 \\
R 4.1 / R 4.10 & 48,32 & 48,32 & 48,32 & 48,32 & 48,32 \\
R 4.9 / R 4.4 & 0,17 & 0,17 & 0,17 & 0,17 & 0,17 \\
R 4.3 / R 4.9 & 0,00 & 0,05 & 0,22 & 0,32 & 0,49 \\
R 4.10/ R 4.9 & 0,03 & 0,03 & 0,03 & 0,03 & 0,03 \\
\hline
\end{tabular}

Com base na Tabela 5.1, nota-se que a glicose é consumida preferencialmente pelas reações 4.4, 4.1 e 4.9, respectivamente, formando ácido lático, ácido butírico e etanol. As reações mais lentas para o consumo de glicose são as 4.2, com formação de ácido acético, e 4.10, com formação de metanol, respectivamente, na maior parte da dimensão longitudinal do reator, exceto nos primeiros $16 \mathrm{~cm}$ onde a velociade de formação de ácido propiônico ( $\mathrm{R}$ 4.3) é nula.

No caso da produção de hidrogênio, as velocidades das reações envolvidas diretamente no processo ( $\mathrm{R} 4.1, \mathrm{R} 4.2, \mathrm{R} 4.3, \mathrm{R} 4.5, \mathrm{R} 4.6, \mathrm{R} 4.7$ e $\mathrm{R} 4.8$ ) também são relacionadas, como mostra a Tabela 5.2.

Tabela 5.2: Relações entre as velocidades das reações de produção direta de $H_{2}$.

\begin{tabular}{lccccc}
\hline Relação & \multicolumn{5}{c}{ Espaço $(\mathrm{cm})$} \\
\cline { 2 - 6 } & 5 & 20 & 35 & 55 & 70 \\
\hline R 4.6 / R 4.8 & 0,00 & 0,00 & 0,00 & 0,00 & 0,00 \\
R 4.8 / R 4.7 & 0,00 & 0,00 & 0,00 & 0,00 & 0,00 \\
R 4.5 / R 4.7 & 0,00 & 0,47 & 1,33 & 1,85 & 2,31 \\
R 4.3 / R 4.5 & 0,00 & 0,03 & 0,03 & 0,03 & 0,03 \\
R 4.1 / R 4.2 & 173,24 & 173,24 & 173,24 & 173,24 & 173,24 \\
R 4.1 / R 4.7 & 0,34 & 0,29 & 0,26 & 0,22 & 0,19 \\
R 4.3 / R 4.7 & 0,00 & 0,01 & 0,04 & 0,05 & 0,07 \\
R 4.5 / R 4.2 & 0,00 & 277,74 & 897,41 & 1486,67 & 2082,10 \\
R 4.5 / R 4.1 & 0,00 & 1,60 & 5,18 & 8,58 & 12,02 \\
\hline
\end{tabular}

Não há produção de $H_{2}$ pelas reações acetogênicas 4.6 e 4.8 .

Entre as velocidades das reações de consumo do gás, a R 4.5 (consome $1 \mathrm{~mol}$ de $H_{2}$ ) é maior que a $\mathrm{R} 4.3$ (consome 2 mols de $H_{2}$ ) ao longo do reator. 
A oxidação do ácido propiônico (reação 4.7) pelas bactérias acetogênicas produtoras de hidrogênio é a via de maior produção de $H_{2}$ no sistema. Esta reação permite a formação de 3 mols de $H_{2}$ por mol de ácido propiônico.

Entretanto, essa produção é prejudicada a partir de $28 \mathrm{~cm}$ do reator devido ao aumento da velocidade da reação de consumo do gás, 4.5, provocado pelo aumento da concentração do ácido lático produzido na reação 4.4.

Portanto, a principal rota metabólica de produção de hidrogênio no reator são as reações $4.4,4.5$ e 4.7

$$
\begin{gathered}
\mathrm{C}_{6} \mathrm{H}_{12} \mathrm{O}_{6} \stackrel{k_{4}}{\rightarrow} 2 \mathrm{C}_{3} \mathrm{H}_{6} \mathrm{O}_{3} \\
\mathrm{C}_{3} \mathrm{H}_{6} \mathrm{O}_{3}+\mathrm{H}_{2} \stackrel{k_{5}}{\longrightarrow} \mathrm{C}_{3} \mathrm{H}_{6} \mathrm{O}_{2}+\mathrm{H}_{2} \mathrm{O} \\
\mathrm{C}_{3} \mathrm{H}_{6} \mathrm{O}_{2}+2 \mathrm{H}_{2} \mathrm{O} \stackrel{k_{7}}{\rightarrow} \mathrm{C}_{2} \mathrm{H}_{4} \mathrm{O}_{2}+\mathrm{CO}_{2}+3 \mathrm{H}_{2}
\end{gathered}
$$

\subsection{Simulação}

A simulação possibilita a análise do comportamento do sistema em diferentes condições de operação.

Nesse sentido, o tempo de detenção hidráulica (TDH) foi simulado com diferentes valores. O TDH utilizado por PEIXOTO (2008) foi 0,5 h. Desta forma, optou-se por analisar o comportamento do reator com $\mathrm{TDH}=0,25 \mathrm{~h}$ e $\mathrm{TDH}=$ $0,75 \mathrm{~h}$.

De acordo com o modelo, as concentrações de ácidos propiônico e acético, e ácidos lático e butírico ao longo do reator para os diferentes valores de TDH são mostrados nas Figuras 5.11 e 5.12, respectivamente. 




Figura 5.11: Simulação do perfil de concentrações de ácidos propiônico e acético.

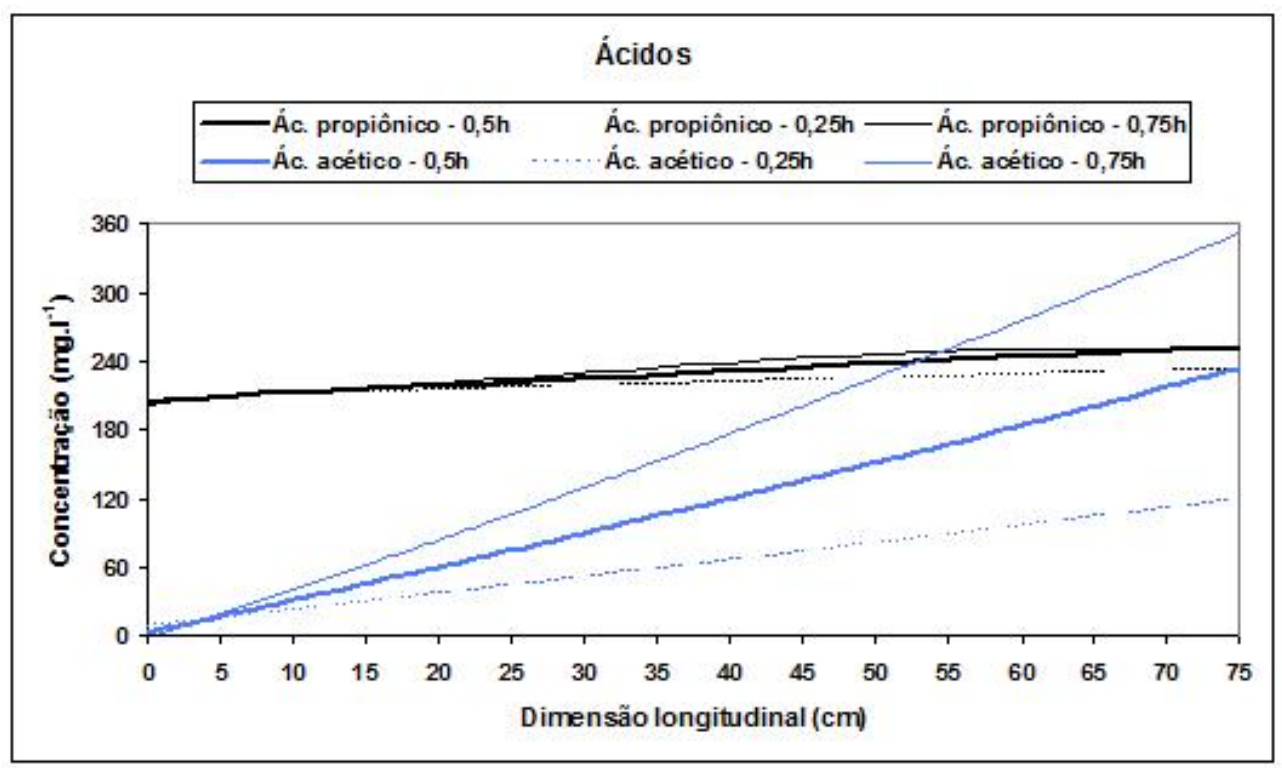

Figura 5.12: Simulação do perfil de concentrações de ácidos lático e butírico. 
Os perfis espaciais das concentrações de álcoois e glicose e da vazão molar de hidrogênio ao longo do reator para os diferentes valores de TDH são mostrados nas Figuras 5.13, 5.14 e 5.15.



Figura 5.13: Simulação do perfil de concentrações de álcoois.



Figura 5.14: Simulação do perfil de concentrações de glicose. 


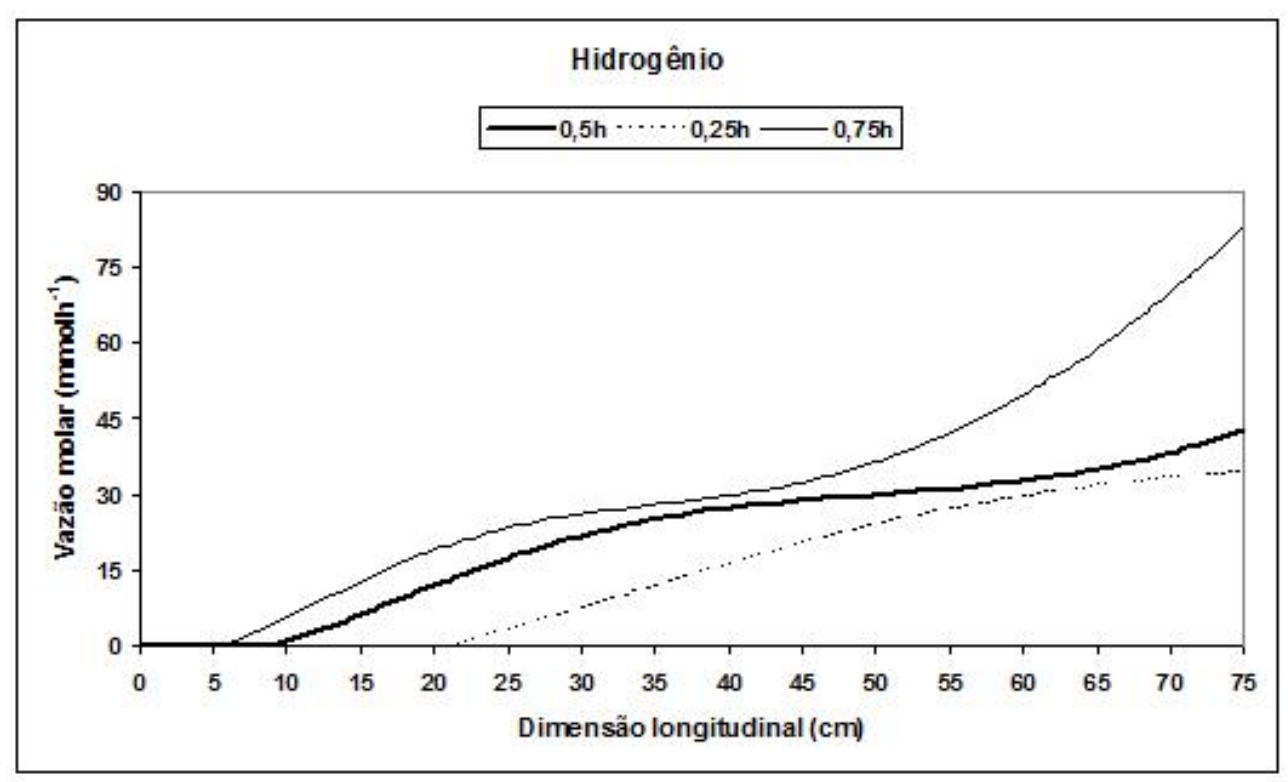

Figura 5.15: Simulação do perfil de vazão molar de hidrogênio.

Com a diminuição do TDH, a concentração da glicose no reator aumenta e a concentração de seus produtos diminuiu, conforme esperado em um sistema ideal. Por outro lado, com o aumento do TDH a concentração da glicose no reator diminuiu e a concentração de seus produtos aumentam.

Alguns fenomênos não abordados no desenvolvimento do modelo, como uma inibição da atividade microbiana , podem influenciar nas concentrações dos compostos.

A simulação seguinte mostra o provável comportamento do reator caso o comprimento fosse duas vezes maior que aquele utilizado e a vazão fosse mantida, ou seja, comprimento $(\mathrm{L})=150 \mathrm{~cm}$ e $\mathrm{TDH}=1 \mathrm{~h}$. A concentração de ácidos resultante é mostrada nas Figuras 5.16 e 5.17. 


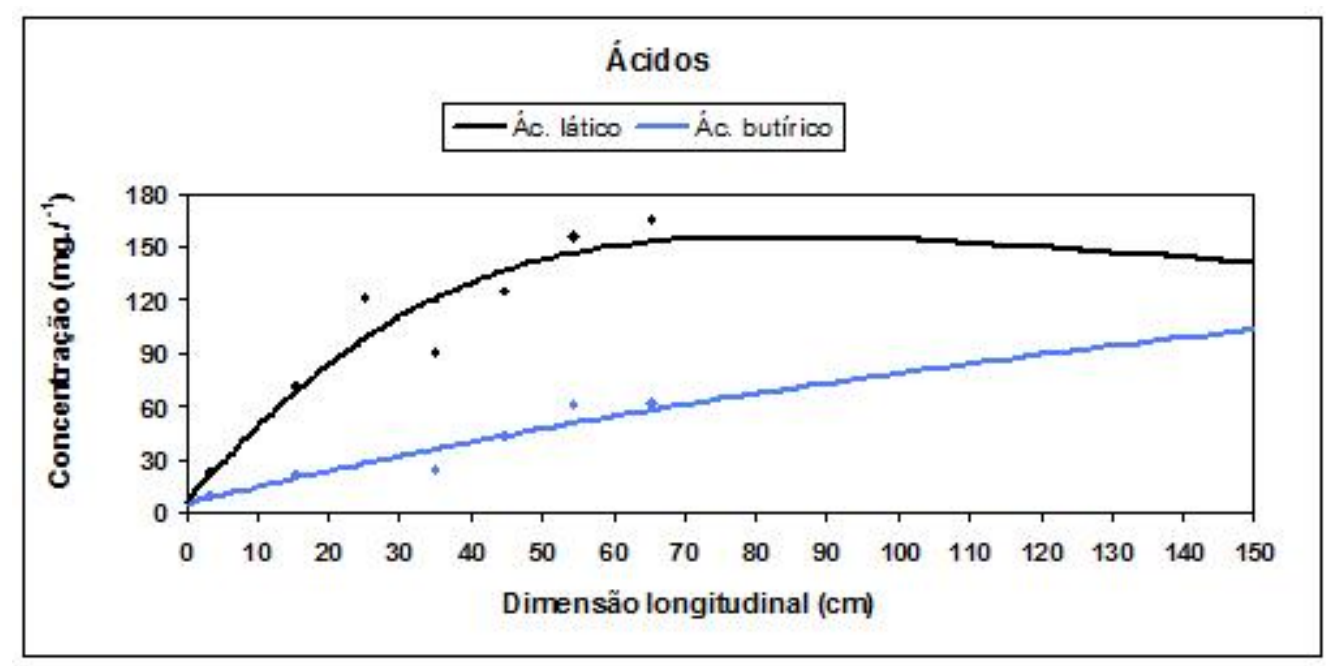

Figura 5.16: Simulação do perfil de concentrações de ácidos para TDH $=1 \mathrm{~h} \mathrm{e} \mathrm{L}=150 \mathrm{~cm}$.

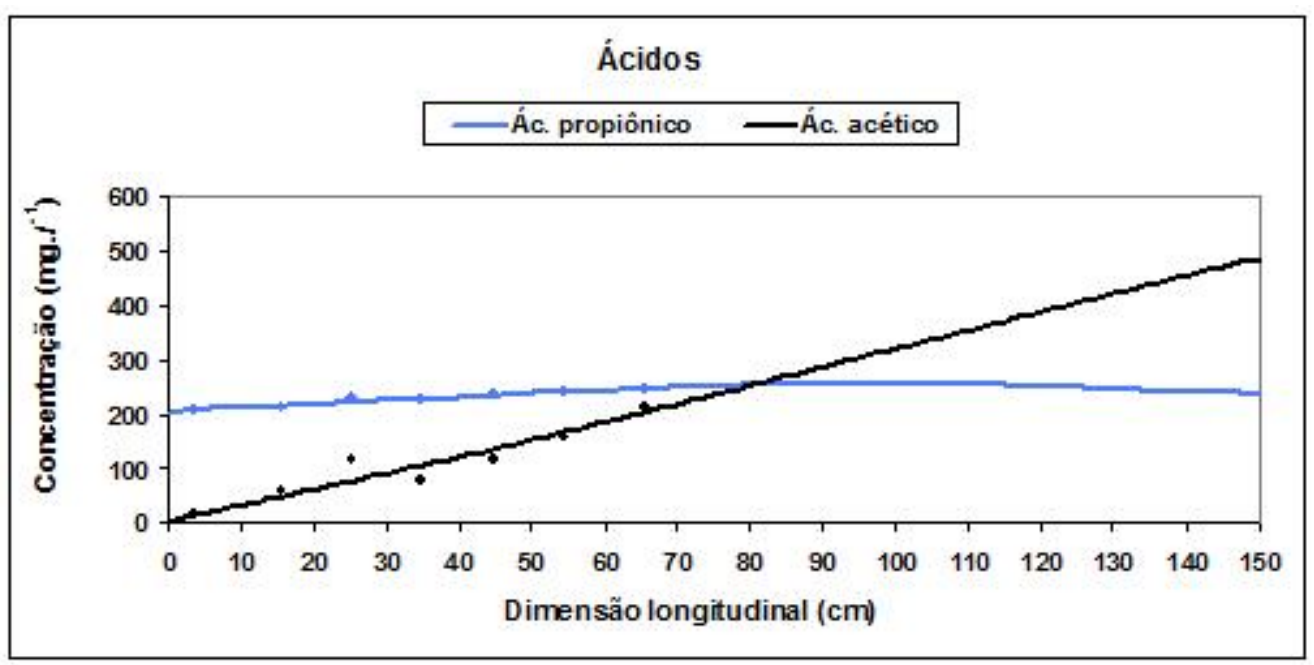

Figura 5.17: Simulação do perfil de concentrações de ácidos para TDH $=1 \mathrm{~h} \mathrm{e} \mathrm{L}=150 \mathrm{~cm}$. 
Para essa condição, os perfis espaciais das concentrações de álcoois e glicose, e da vazão molar de hidrogênio são mostrados nas Figuras 5.18, 5.19 e 5.20.

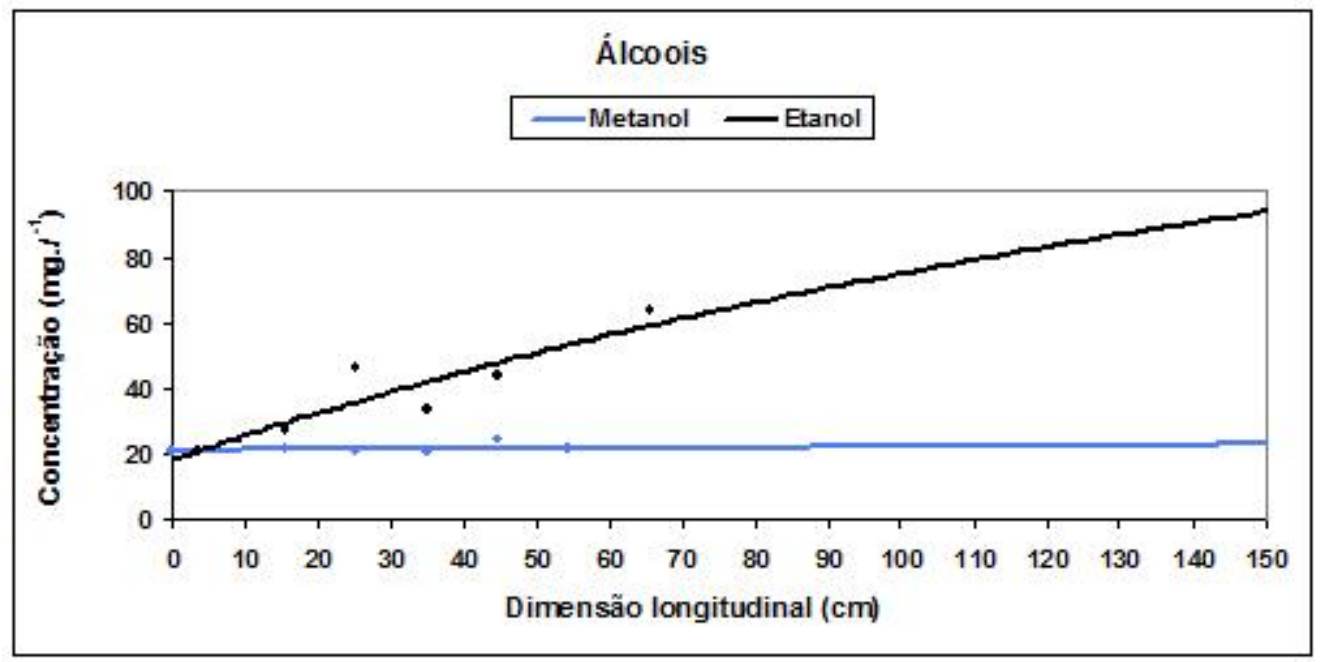

Figura 5.18: Simulação do perfil de concentrações de álcoois para $T D H=1 \mathrm{~h} \mathrm{e} L=150 \mathrm{~cm}$.

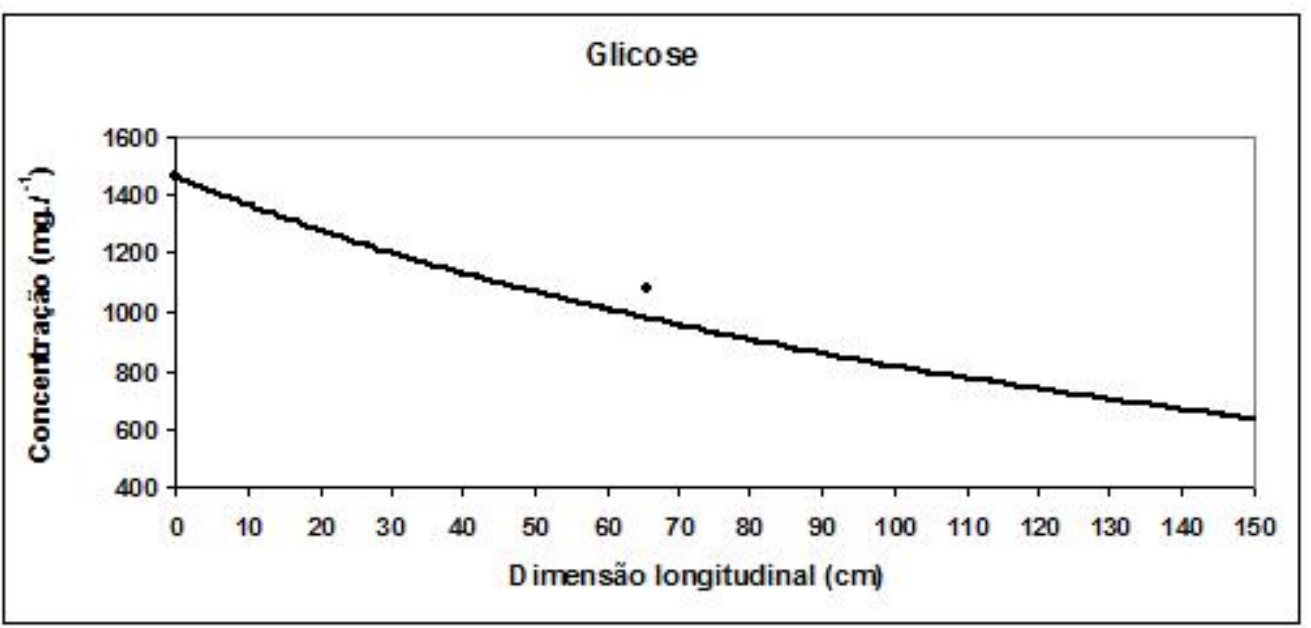

Figura 5.19: Simulação do perfil de concentrações de glicose para $T D H=1 \mathrm{~h}$ e $\mathrm{L}=150 \mathrm{~cm}$.

A concentração de glicose no efluente é igual a 635,9 mg/l e a produção de $H_{2}$ é de $245,6 \mathrm{mmol} / \mathrm{h}$.

$\mathrm{O}$ crescimento exponencial da curva do $\mathrm{H}_{2}$ na segunda metade do reator pode ser provocado pelo declínio da concentração de ácido lático. 




Figura 5.20: Simulação do perfil de vazão molar de hidrogênio para $T D H=1 \mathrm{~h}$ e $\mathrm{L}=150 \mathrm{~cm}$.

A simulação da produção de hidrogênio para diferentes valores de TDH é mostrada na Figura 5.21. Nota-se que a produção máxima é alcançada em aproximadamente $\mathrm{TDH}=2 \mathrm{~h}$. A partir deste valor a produção diminui.



Figura 5.21: Simulação do perfil de vazão molar de hidrogênio para diferentes valores de TDH. 


\section{Capítulo 6}

\section{Conclusões}

A solução do sistema de equações descritivas do modelo convergiu com o uso da técnica da geração de números aleatórios e métodos de resolução numérica. Outras tentativas (técnica) foram empregadas, porém, não foram obtidos resultados fisicamente plausíveis.

A pequena diferença entre os dados experimentais e o modelo desenvolvido deve-se às simplificações consideradas na modelagem, a erros decorrentes do método de resolução e a erros na estimativa dos parâmetros do sistema.

O modelo matemático proposto revelou-se bastante adequado para a previsão do perfil de concentrações ao longo da dimensão longitudinal do reator, e possibilitou a representação das rotas metabólicas de utilização da matéria orgânica no reator.

A reação de oxidação do ácido propiônico pelas bactérias acidogênicas produtoras de hidrogênio constitui a principal via de produção de $H_{2}$ no sistema. Embora esta reação permita a formação de $3 \mathrm{~mol}$ de $H_{2}$ por mol de ácido propiônico, o rendimento do sistema é prejudicado pelo aumento da velocidade da reação de consumo do gás, 4.5, provocado pelo aumento da concentração do ácido lático produzido na reação 4.4 .

Portanto, a principal rota metabólica de produção de hidrogênio no reator são as reações: 


$$
\begin{gathered}
\mathrm{C}_{6} \mathrm{H}_{12} \mathrm{O}_{6} \stackrel{k_{4}}{\rightarrow} 2 \mathrm{C}_{3} \mathrm{H}_{6} \mathrm{O}_{3} \\
\mathrm{C}_{3} \mathrm{H}_{6} \mathrm{O}_{3}+\mathrm{H}_{2} \stackrel{k_{5}}{\rightarrow} \mathrm{C}_{3} \mathrm{H}_{6} \mathrm{O}_{2}+\mathrm{H}_{2} \mathrm{O} \\
\mathrm{C}_{3} \mathrm{H}_{6} \mathrm{O}_{2}+2 \mathrm{H}_{2} \mathrm{O} \stackrel{k_{7}}{\rightarrow} \mathrm{C}_{2} \mathrm{H}_{4} \mathrm{O}_{2}+\mathrm{CO}_{2}+3 \mathrm{H}_{2}
\end{gathered}
$$




\section{Capítulo 7}

\section{Sugestões de Continuidade}

O modelo descrito foi desenvolvido e calibrado adequadamente, apresentandose coerente com os dados experimentais. Entretanto, a disponibilidade de dados foi pequena, impossibilitando a validação.

Sugere-se a obtenção de conjuntos de dados experimentais para que outros pesquisadores possam solidificar a etapa de calibração e possibilitar a validação do modelo.

Sugere-se também a implementação do modelo considerando fenômenos não abordados no presente trabalho. 


\section{Referências Bibliográficas}

CABRAL, A. K. A. (1995). Caracterização hidrodinâmica de um reator anaeróbio horizontal de leito fixo (RAHLF). Dissertação de mestrado, Escola de Engenharia de São Carlos, USP, São Carlos.

CHERNICHARO, A. L. (1997). Principios do tratamento biológico de águas residuárias. Reatores anaeróbios, volume 5. Departamento de Engenharia Sanitária e Ambiental - DESA. Universidade Federal de Minas Gerais, Minas Gerais.

CHRISTOFOLETTI, A. (2004). Modelagem de sistemas ambientais. Edgard Blücher, São Paulo.

Costello, D. J., GREenfield, P. F., \& LEE, P. L. (1991). Dynamic modelling of a single-stage high-rate anaerobic reactor-I. Model derivation. Water Research, 25(7):847-858.

DAVILA-VAZQUEZ, G., ARRIGA, S., MONDRAGÓN, F. A., RODRÍGUEZ, A. L., COLUNGA, L. M. R., \& FLORES, E. R. (2008). Fermentative biohydrogen production: trends and perspectives. Bioresource Technology, 7:27-45.

DEAN, J. A. (1987). Handbook of Organic Chemistry. McGraw-Hill Book Company.

Dubois, S. M., Gilles, K. A., HAMilton, J. L., REBERS, P. A., \& SMITH, F. (1956). Colorimetric methods for determination of sugar and related substance. Analytical Chemistry, 228:13-21.

Energy Agency International (2005). World Energy Outlook 2004. Nuclear Energy Agency and the International Atomic Energy Agency. 
Energy Watch Group (2006). Uranium resources and nuclear energy, EWGSeries No. 1.

Energy Watch Group (2007). Coal: resources and future production, EWGSeries No.1.

GAVAlA, H. N., SKIADAS, I. O., \& AHRING, B. K. (2005). Biological hydrogen production in suspended and attached growth anaerobic reactor system. International Journal of Hydrogen Energy, 31:1164-1175.

HAWKES, F. R., DINSDALE, R., HAWKES, D. L., \& HUSSY, I. (2002). Sustainable fermentative hydrogen production: challenges for process optimization. International Journal of Hydrogen Energy, 27:1339-1347.

International Atomic Energy Agency (2007). Nuclear Energy Agency and the International Atomic Energy Agency, em http://www.iaea.org/ cgi-bin/db.page.pl/pris.oprconst.htmi.

JORGENSEN, S. E. \& GROMIEC, M. J. (1985). Mathematical models in biological wastewater treatment. Developments in environmental modeling 7. Elsevier.

KHANAL, S. K., CHEN, W. H., LI, L., \& SUNG, S. (2004). Biological hydrogen production: effects of $\mathrm{pH}$ and intermediate products. International Journal of Hydrogen Energy, 29:1123-1131.

KOTAY, S. M. \& DAS, D. (2008). Biohydrogen as a renewable energy resource - Prospects and potencials. International Journal of Hydrogen Energy, 33:258263.

LAY, J. J., LEE, Y. J., \& NOIKE, T. (1999). Feasibility of biological hydrogen production from organic fraction of municipal solid waste. Water Res., 33:25792586.

LEE, C. (1973). Models in Planning. An introduction to the use of quantitative models in planning. Oxford. Pergamon Press. 
LetTingA, G., HUlShOfPOL, L. W., \& ZEEMAN, G. (1996). Part 1: Anaerobic wastewater treatment. In Biological Wastewater Treatment. Lacture notes. Wageningen Agricultural University, ed. January 1996.

LEVENSPIEL, O. (1999). Engenharia das Reações Químicas: Cálculo de reatores. Edgard Blucher, São Paulo.

MIZUNO, O., DINSDALE, R., HAWKES, F. R., HAWKES, D. L., \& NOIKE, T. (2000). Enhancement of hydrogen production from glucose by nitrogen gas sparging. Bioresource Technology, 73:59-65.

MOSEY, F. E. (1982). New developments in the anaerobic treatment of industrial wastes. Water Pollution Control, 81:540-552.

MOSEY, F. E. (1983). Mathematical modeling of the anaerobic process: regulatory mechanisms for the formation of short-chain volatile acids from glucose. Water Science and Thecnology, 15:209-232.

OLSSON, G. \& NEWELL, B. (1999). Wastewater Treatment Systems. Modelling, Diagnosis and Control. IWA Publishing.

PEIXOTO, G. (2008). Produção de hidrogênio em reator anaeróbio de leito fixo e fluxo ascendente a partir de água residuária de indústria de refrigerantes. Dissertação de mestrado, Escola de Engenharia de São Carlos, USP, São Carlos.

PINTO, J. C. \& LAGE, P. L. C. (2001). Métodos numéricos em problemas de engenharia química. E-papers Serviços Editoriais Ltda, Rio de Janeiro.

SHIDA, G. M. (2008). Produção de hidrogênio e ácidos orgânicos por fermentação acidogênica em reator anaeróbio de leito fluidificado. Dissertação de mestrado, Escola de Engenharia de São Carlos, USP, São Carlos.

TUCCI, C. E. M. (1998). Modelos Hidrológicos. Editora da Universidade UFRGS, Porto Alegre. 
VAN-GINKEL, S. \& LOGAN, B. E. (2005). Inhibition of biohydrogen production by undissociated acetic and butyric acids. Environmental Science and Technology, 39:9351-9356.

VAN-GINKEL, S., SUNG, S., \& LAY, J. J. (2001). Biohydrogen production as a function of $\mathrm{pH}$ and substrate concentration. Environmental Science and Technology, 35:4726-4730.

WENDLAND, E. \& RUBER, O. (1998). Hidrogeologishe Modelle. Lehrstuhl fur hidrogeologie, Ruhr-Universitat Bochum.

WENDT, H., GOTZ, M., \& LINARDI, M. (2000). Tecnologia de células a combustível. Química Nova, 3:538-546.

WENTZEL, M. C. \& EKAMA, G. A. (1997). Principles in the modelling of biological wastewater treatment plants. In CLOETE, T. E. \& MUYIMA, N. Y. O., editors, Microbial community analysis: the key to the design of biological wastewater treatment systems. Scientific and Technical Report, number 5. International Association on Water Quality.

ZAIAT, M. (1996). Desenvolvimento de reator anaeróbio horizontal de leito fixo (RAHLF) para tratamento de águas residuárias. Tese de doutorado, Escola de Engenharia de São Carlos, USP, São Carlos.

ZAIAT, M., VIEIRA, L. G. T., \& FORESTI, E. (1997). Intrinsec kinetic parameters of substrate utilization by immobilized anaerobic sludge. Biotechnology and Bioengineering, 53:220-225.

ZERTA, M., SCHIMIDT, P. R., STILlER, C., \& HUBERT, L. (2008). Alternative World Energy Outlook (AWEO) and the role of hydrogen in a changing energy landscape. International Journal of Hydrogen Energy, 33:30213025. 